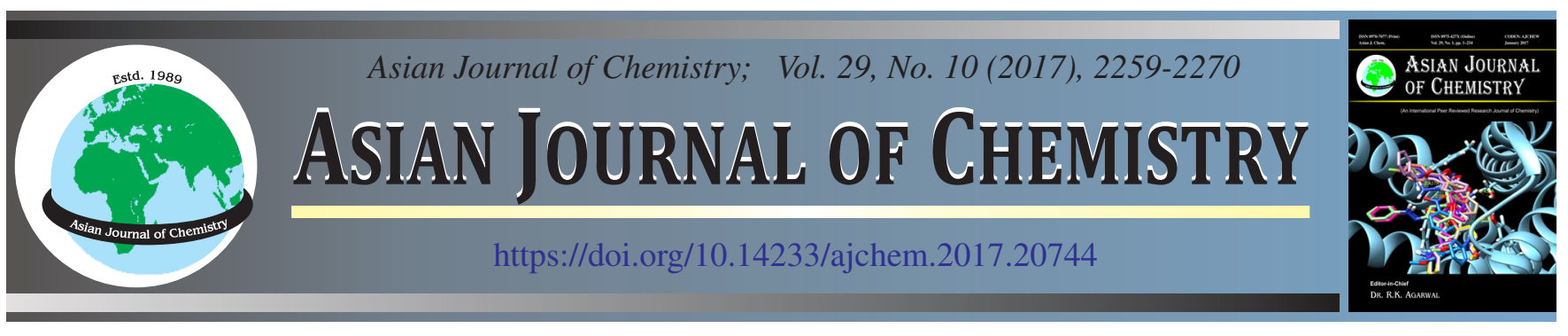

\title{
Photophysical and Electroluminescence Properties of Some 2-(5,6-Dihydrobenzimidazo[1,2-c]quinazolin-6-yl)-5-substituted Phenol Schiff Bases Derivatives toward Organic Light Emitting Diodes: DFT Study
}

\begin{abstract}
NASER Eltaher Eltayeb
Department of Chemistry, Rabigh College of Science and Arts, P.O. Box 344, King Abdulaziz University, Jeddah, Saudi Arabia

Corresponding author: E-mail: netaha@kau.edu.sa; nasertaha90@yahoo.co.uk; nasertaha90@hotmail.com

Received: 2 May 2017;

Accepted: 15 July 2017;

Published online: 31 August 2017;

AJC-18531

In this contribution, a computational study of 2-(5,6-dihydrobenzimidazo[1,2-c]quinazolin-6-yl)-5-substitutedphenol derivatives, namely; 2-(5,6-dihydrobenzimidazo[1,2-c] quinazolin-6-yl)phenol (L-H), 2-(5,6-dihydrobenzimidazo[1,2-c]quinazolin-6-yl)-5-bromophenol (L-Br) and 2-(5,6-dihydrobenzimidazo[1,2-c]quinazolin-6-yl)-5-methoxyphenol $\left(\mathbf{L}-\mathbf{O} \mathbf{C H}_{3}\right)$ are presented as organic light emitting diodes (OLED) materials. The geometries of the molecules $\mathbf{L}-\mathbf{H}, \mathbf{L}-\mathbf{B r}$ and $\mathbf{L}-\mathbf{O C H}_{3}$ were optimized using density functional theory (DFT) at the B3LYP/ $6-31++G(d, p)$ level of theory. The theoretical vibrational frequencies were obtained by DFT calculations. The electronic structures were described in terms of the distribution of the highest occupied molecular orbital (HOMO) and the lowest unoccupied molecular orbital (LUMO). TD-DFT at the B3LYP/6-31++G(d,p) level of theory was used to investigate the electronic spectra and to optimize the excited state. The ionization potential and electron affinity were calculated to gain insights into the hole/electron transport.The effect of electric field and its direction on the spatial distribution of HOMO and LUMO and the dipole moment were studied. Our findings suggest that the substituted derivatives of 2-(5,6-dihydrobenzimidazo[1,2-c]quinazolin-6-yl)-5-substituted phenol; $\mathbf{L}-\mathbf{H}, \mathbf{L}-\mathbf{B r}$ and $\mathbf{L}-\mathbf{O C H} \mathbf{C H}_{3}$ can be used as promising electron transport materials for organic light emitting diodes (OLED).
\end{abstract}

Keywords: Electroluminescence, 2-(5,6-Dihydrobenzimidazo[1,2-c]quinazolin-6-yl)-5-substituted phenol, Organic light emitting diodes.

\section{INTRODUCTION}

Organic light emitting diodes (OLEDs) have been discovered by Tang and Van Slyke [1,2]. Since then, they have been the center of studies around the globe because of their important applications in full-colour displays and lighting sources. Nowadays organic light emitting diodes (OLED) applications cover wide range of displays such as mobile phones, TV, notebooks, tablets, digital cameras and automotives. Organic lightemitting diodes have the advantage to make full colour largeflat-panel displays on low-cost flexible substrates [3]. OLED device can be made of organic hole-and electron-transporting layer sandwiches between two metal electrodes. Comparing with hole-transporting materials, a few good electron-transporting materials (ETMs) were reported. ETMs have outstanding electron transporting properties that are required to improve the efficiency of OLED devices [4]. Benzimidazole derivatives as electron transporting materials with highly efficient OLED device were reported [5]. Benzimidazole and its derivatives showed different fluorescence efficiencies, based on their molecular structures. Therefore, designing of new materials based on changing the molecular structure is the suitable way for the invention of novel efficient materials [6]. Recently, several studies have been reported on the influence of changing the linking modes in the chemical structure of the benzimidazole compounds and their effect on the thermal, photophysical, electrochemical and charge transport properties [7]. The purpose of this article is to use the computational calculations based on density functional theory (DFT) to study the effect of the substituents on 2-(5,6dihydrobenzimidazo[1,2-c] quinazolin-6-yl)-5-substituted phenol and to investigate their properties as charge transporting materials to improve design and performance of OLED devices.

\section{COMPUTATIONAL METHODS}

Molecular electronic structure calculations were performed using the density functional theory (DFT) and time dependentdensity functional theory (TD-DFT). The DFT calculations were done by Becke's three-parameter exchange functional with Lee-Yang-Parr (LYP) correlation functional. Gaussian 09 software [8] were used to performed full geometry optimizations of substituted phenol; $\mathbf{L}-\mathbf{H}, \mathbf{L}-\mathbf{B r}, \mathbf{L}-\mathbf{O C H}_{3}$ at the B3LYP level of theory using an 6-31++G(d,p) basis set. The optimization was confirmed with absence of negative frequency. The optimized geometries were then employed to calculate UV-visible 
electronic absorption at the B3LYP/6-31++G(d,p) level of theory. The softwares; Chemcraft [9] and GaussSum [10] were used to analysis of Gaussian 09 output files. The reorganization energy for electron $\left(\lambda_{\mathrm{e}}\right)$ and hole $\left(\lambda_{\mathrm{h}}\right)$ of the molecules have been predicted from the single point energy at the B3LYP/6$31++\mathrm{G}(\mathrm{d}, \mathrm{p})$ level based on $6-31++\mathrm{G}(\mathrm{d}, \mathrm{p})$ optimized neutral, cationic and anionic geometries [11].

The values for adiabatic ionization potential (IP) and adiabatic electron affinity (EA) of the molecules were calculated as using Equations (1) and (2).

$$
\begin{aligned}
& \mathrm{IP}=\mathrm{E}\left(\mathrm{M}^{+}\right)-\mathrm{E}\left(\mathrm{M}^{0}\right) \\
& \mathrm{EA}=\mathrm{E}\left(\mathrm{M}^{0}\right)-\mathrm{E}\left(\mathrm{M}^{-}\right)
\end{aligned}
$$

where $\mathrm{E}\left(\mathrm{M}^{0}\right), \mathrm{E}\left(\mathrm{M}^{+}\right)$and $\mathrm{E}\left(\mathrm{M}^{-}\right)$are the total energies of the neutral, cationic and anionic forms of the molecules at the B3LYP/6-31++G(d,p) level, respectively [12].

Molecule L-H was selected for further investigation of electrical behaviour, the. $3.0 \mathrm{~V} / \AA \AA^{\circ}$ uniform electric field was applied along the $\pm \mathrm{X}, \pm \mathrm{Y}$ and $\pm \mathrm{Z}$ directions. The effect of electrical field was studied by determination of the spatial distribution of frontier molecular orbitals and dipole moment. The field direction which showed highest effect was selected for further investigation of the effect of change in the electric field on both the spatial distribution and the energies of molecular orbitals [13].

\section{RESULTS AND DISCUSSION}

Geometries of the ground state $\left(\mathrm{S}_{\mathbf{0}}\right)$ and singlet excited state $\left(\mathbf{S}_{\mathbf{1}}\right)$ : The geometry optimization had been performed using density functional theory (DFT) with B3LYP method at the $6-31++\mathrm{G}(\mathrm{d}, \mathrm{p})$ basis set. The optimized structures of the three molecules 2-(5,6-dihydrobenzimidazo[1,2-c]-quinazolin6-yl)-5-substituted phenol; L-H, L-Br and $\mathbf{L - O C H}$ had been confirmed with the absence of imaginary frequency. Fig. 1 showed that the overlay of the optimized geometry with the crystal structure of the molecule L-H. This can be easily seen for the optimization performed by B3LYP method at the 6$31++\mathrm{G}(\mathrm{d}, \mathrm{p})$ basis set which produced a good structure comparable with crystal structure [14]. Tables 1 and 2 showed the

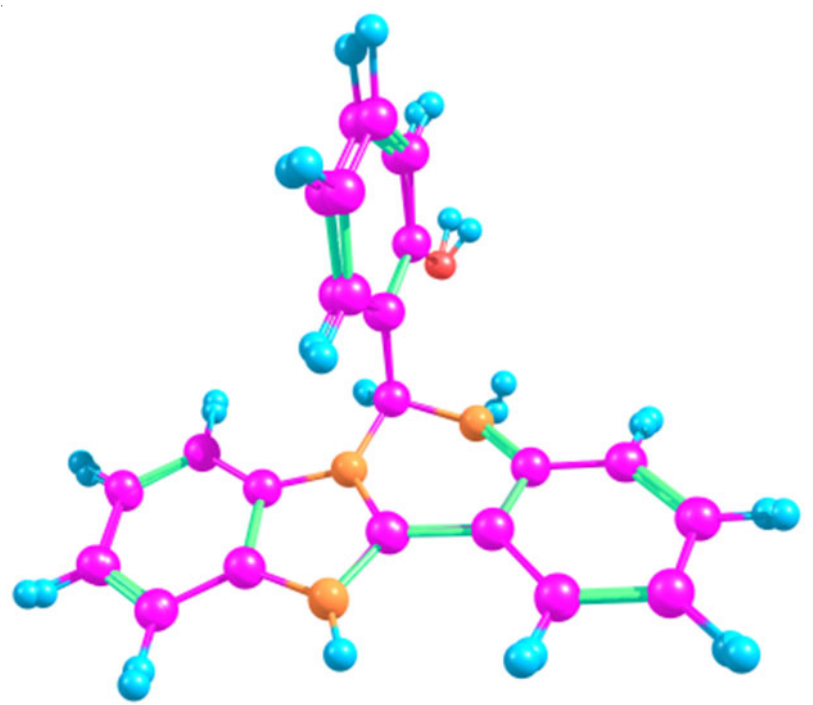

Fig. 1. Overlay of optimized ground state geometry with the crystal structure of molecule L-H
TABLE-1

COMPARISON OF BOND LENGTHS AND ANGLES FOR

\begin{tabular}{|c|c|c|c|c|c|}
\hline \multicolumn{2}{|c|}{ L-H } & \multicolumn{2}{|c|}{ L-Br } & \multicolumn{2}{|c|}{$\mathrm{L}-\mathrm{OCH}_{3}$} \\
\hline$R(1-22)$ & 1.381 & $\mathrm{R}(1-22)$ & 1.379 & $\mathrm{R}(1-22)$ & 1.385 \\
\hline$R(1-36)$ & 0.966 & $R(1-36)$ & 0.966 & $\mathrm{R}(1-36)$ & 0.966 \\
\hline$R(2-5)$ & 1.385 & $R(2-5)$ & 1.386 & $R(2-5)$ & 1.385 \\
\hline $\mathrm{R}(2-12)$ & 1.388 & $\mathrm{R}(2-12)$ & 1.389 & $\mathrm{R}(2-12)$ & 1.388 \\
\hline $\mathrm{R}(2-19)$ & 1.452 & $\mathrm{R}(2-19)$ & 1.45 & $\mathrm{R}(2-19)$ & 1.451 \\
\hline $\mathrm{R}(3-18)$ & 1.397 & $\mathrm{R}(3-18)$ & 1.398 & $\mathrm{R}(3-18)$ & 1.397 \\
\hline $\mathrm{R}(3-19)$ & 1.466 & $\mathrm{R}(3-19)$ & 1.465 & $\mathrm{R}(3-19)$ & 1.466 \\
\hline $\mathrm{R}(3-38)$ & 1.012 & $\mathrm{R}(3-38)$ & 1.012 & $\mathrm{R}(3-38)$ & 1.013 \\
\hline $\mathrm{R}(4-11)$ & 1.385 & $\mathrm{R}(4-11)$ & 1.385 & $\mathrm{R}(4-11)$ & 1.385 \\
\hline $\mathrm{R}(4-12)$ & 1.318 & $\mathrm{R}(4-12)$ & 1.318 & $\mathrm{R}(4-12)$ & 1.318 \\
\hline$R(5-6)$ & 1.397 & $R(5-6)$ & 1.396 & $R(5-6)$ & 1.396 \\
\hline $\mathrm{R}(5-11)$ & 1.42 & $\mathrm{R}(5-11)$ & 1.42 & $\mathrm{R}(5-11)$ & 1.42 \\
\hline$R(6-7)$ & 1.396 & $R(6-7)$ & 1.396 & $R(6-7)$ & 1.396 \\
\hline$R(6-32)$ & 1.086 & $R(6-32)$ & 1.086 & $R(6-32)$ & 1.086 \\
\hline$R(7-8)$ & 1.411 & $R(7-8)$ & 1.411 & $R(7-8)$ & 1.411 \\
\hline$R(7-33)$ & 1.086 & $R(7-33)$ & 1.086 & $\mathrm{R}(7-33)$ & 1.086 \\
\hline $\mathrm{R}(8-9)$ & 1.393 & $R(8-9)$ & 1.393 & $R(8-9)$ & 1.393 \\
\hline $\mathrm{R}(8-30)$ & 1.086 & $\mathrm{R}(8-30)$ & 1.086 & $\mathrm{R}(8-30)$ & 1.086 \\
\hline $\mathrm{R}(9-10)$ & 1.085 & $\mathrm{R}(9-10)$ & 1.085 & $\mathrm{R}(9-10)$ & 1.085 \\
\hline $\mathrm{R}(9-11)$ & 1.402 & $\mathrm{R}(9-11)$ & 1.402 & $\mathrm{R}(9-11)$ & 1.402 \\
\hline $\mathrm{R}(12-13)$ & 1.454 & $\mathrm{R}(12-13)$ & 1.454 & $\mathrm{R}(12-13)$ & 1.454 \\
\hline $\mathrm{R}(13-14)$ & 1.401 & $\mathrm{R}(13-14)$ & 1.401 & $\mathrm{R}(13-14)$ & 1.401 \\
\hline $\mathrm{R}(13-18)$ & 1.415 & $\mathrm{R}(13-18)$ & 1.415 & $\mathrm{R}(13-18)$ & 1.415 \\
\hline $\mathrm{R}(14-15)$ & 1.392 & $\mathrm{R}(14-15)$ & 1.392 & $\mathrm{R}(14-15)$ & 1.392 \\
\hline $\mathrm{R}(14-37)$ & 1.085 & $\mathrm{R}(14-37)$ & 1.085 & $\mathrm{R}(14-37)$ & 1.085 \\
\hline $\mathrm{R}(15-16)$ & 1.402 & $\mathrm{R}(15-16)$ & 1.402 & $\mathrm{R}(15-16)$ & 1.402 \\
\hline $\mathrm{R}(15-35)$ & 1.085 & $\mathrm{R}(15-35)$ & 1.085 & $\mathrm{R}(15-35)$ & 1.085 \\
\hline $\mathrm{R}(16-17)$ & 1.394 & $\mathrm{R}(16-17)$ & 1.394 & $\mathrm{R}(16-17)$ & 1.394 \\
\hline $\mathrm{R}(16-31)$ & 1.086 & $\mathrm{R}(16-31)$ & 1.086 & $\mathrm{R}(16-31)$ & 1.086 \\
\hline $\mathrm{R}(17-18)$ & 1.404 & $\mathrm{R}(17-18)$ & 1.403 & $\mathrm{R}(17-18)$ & 1.404 \\
\hline $\mathrm{R}(17-34)$ & 1.087 & $\mathrm{R}(17-34)$ & 1.087 & $\mathrm{R}(17-34)$ & 1.087 \\
\hline $\mathrm{R}(19-20)$ & 1.095 & $\mathrm{R}(19-20)$ & 1.095 & $\mathrm{R}(19-20)$ & 1.095 \\
\hline $\mathrm{R}(19-21)$ & 1.534 & $\mathrm{R}(19-21)$ & 1.536 & $\mathrm{R}(19-21)$ & 1.535 \\
\hline $\mathrm{R}(21-22)$ & 1.405 & $\mathrm{R}(21-22)$ & 1.405 & $\mathrm{R}(21-22)$ & 1.408 \\
\hline $\mathrm{R}(21-26)$ & 1.397 & $R(21-26)$ & 1.396 & $\mathrm{R}(21-26)$ & 1.391 \\
\hline $\mathrm{R}(22-23)$ & 1.395 & $\mathrm{R}(22-23)$ & 1.394 & $\mathrm{R}(22-23)$ & 1.389 \\
\hline $\mathrm{R}(23-24)$ & 1.397 & $\mathrm{R}(23-24)$ & 1.396 & $\mathrm{R}(23-24)$ & 1.402 \\
\hline $\mathrm{R}(23-29)$ & 1.088 & $\mathrm{R}(23-29)$ & 1.088 & $\mathrm{R}(23-29)$ & 1.088 \\
\hline $\mathrm{R}(24-25)$ & 1.395 & $\mathrm{R}(24-25)$ & 1.392 & $\mathrm{R}(24-25)$ & 1.397 \\
\hline $\mathrm{R}(24-27)$ & 1.086 & $\mathrm{R}(24-27)$ & 1.084 & $\mathrm{R}(24-27)$ & 1.083 \\
\hline $\mathrm{R}(25-26)$ & 1.398 & $R(25-26)$ & 1.395 & $R(25-26)$ & 1.404 \\
\hline $\mathrm{R}(25-39)$ & 1.085 & $\mathrm{R}(25-39)$ & 1.904 & $\mathrm{R}(25-39)$ & 1.368 \\
\hline $\mathrm{R}(26-28)$ & 1.085 & $\mathrm{R}(26-28)$ & 1.083 & $\mathrm{R}(26-28)$ & 1.084 \\
\hline $\mathrm{A}(22-1-36)$ & 110.1 & $\mathrm{~A}(22-1-36)$ & 110.3 & $\mathrm{R}(39-40)$ & 1.421 \\
\hline $\mathrm{A}(1-22-21)$ & 116.6 & $\mathrm{~A}(1-22-21)$ & 116.6 & $\mathrm{R}(40-41)$ & 1.091 \\
\hline$A(1-22-23)$ & 122.1 & $\mathrm{~A}(1-22-23)$ & 122.4 & $\mathrm{R}(40-42)$ & 1.098 \\
\hline$A(5-2-12)$ & 106.9 & $A(5-2-12)$ & 106.9 & $R(40-43)$ & 1.098 \\
\hline $\mathrm{A}(5-2-19)$ & 129 & $\mathrm{~A}(5-2-19)$ & 129 & $\mathrm{~A}(22-1-36)$ & 110 \\
\hline$A(2-5-6)$ & 132.8 & $A(2-5-6)$ & 132.8 & $\mathrm{~A}(1-22-21)$ & 116.7 \\
\hline $\mathrm{A}(2-5-11)$ & 104.6 & $\mathrm{~A}(2-5-11)$ & 104.5 & $\mathrm{~A}(1-22-23)$ & 122.8 \\
\hline $\mathrm{A}(12-2-19)$ & 123.6 & $\mathrm{~A}(12-2-19)$ & 123.6 & $A(5-2-12)$ & 106.9 \\
\hline$A(2-12-4)$ & 112.9 & $\mathrm{~A}(2-12-4)$ & 112.9 & $A(5-2-19)$ & 129 \\
\hline $\mathrm{A}(2-12-13)$ & 118.3 & $\mathrm{~A}(2-12-13)$ & 118.3 & $A(2-5-6)$ & 132.8 \\
\hline $\mathrm{A}(2-19-3)$ & 107 & $\mathrm{~A}(2-19-3)$ & 107.1 & $\mathrm{~A}(2-5-11)$ & 104.6 \\
\hline $\mathrm{A}(2-19-20)$ & 108.1 & $\mathrm{~A}(2-19-20)$ & 108.3 & $\mathrm{~A}(12-2-19)$ & 123.7 \\
\hline $\mathrm{A}(2-19-21)$ & 112.9 & $\mathrm{~A}(2-19-21)$ & 112.9 & $\mathrm{~A}(2-12-4)$ & 112.9 \\
\hline $\mathrm{A}(18-3-19)$ & 119.2 & $\mathrm{~A}(18-3-19)$ & 119 & $\mathrm{~A}(2-12-13)$ & 118.3 \\
\hline $\mathrm{A}(18-3-38)$ & 115.3 & $\mathrm{~A}(18-3-38)$ & 115.3 & $\mathrm{~A}(2-19-3)$ & 107 \\
\hline $\mathrm{A}(3-18-13)$ & 119.1 & $\mathrm{~A}(3-18-13)$ & 119 & $\mathrm{~A}(2-19-20)$ & 108.1 \\
\hline $\mathrm{A}(3-18-17)$ & 121.6 & $\mathrm{~A}(3-18-17)$ & 121.7 & $\mathrm{~A}(2-19-21)$ & 113.2 \\
\hline
\end{tabular}
COMPOUNDS L-H, L-Br AND L-OCH $\mathrm{H}_{3}$ IN GROUND STATE 


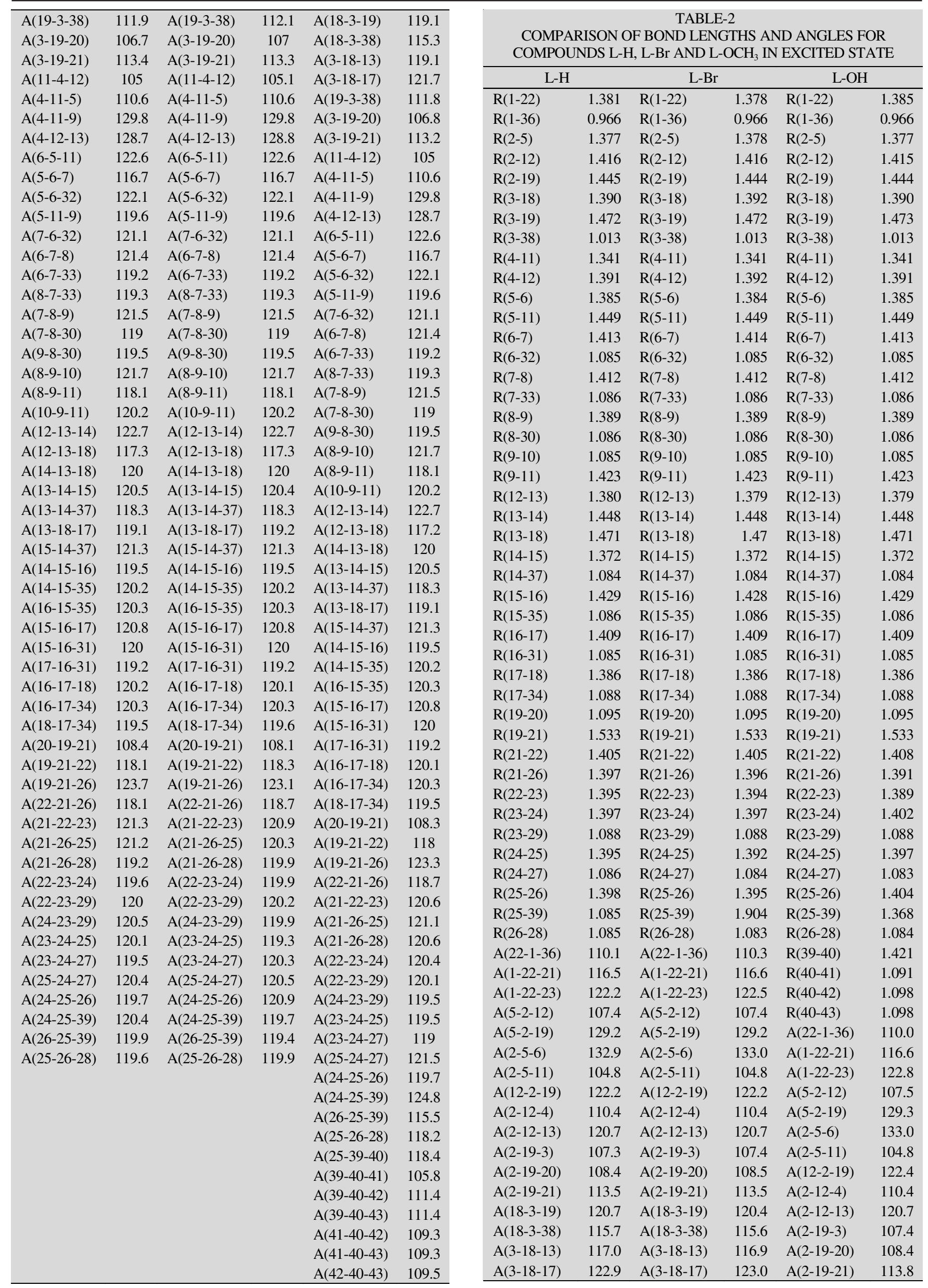




\begin{tabular}{|c|c|c|c|c|c|}
\hline $\mathrm{A}(19-3-38)$ & 112.1 & $\mathrm{~A}(19-3-38)$ & 112.2 & $\mathrm{~A}(18-3-19)$ & 120.6 \\
\hline $\mathrm{A}(3-19-20)$ & 106.5 & $\mathrm{~A}(3-19-20)$ & 106.7 & $\mathrm{~A}(18-3-38)$ & 115.7 \\
\hline $\mathrm{A}(3-19-21)$ & 112.5 & $\mathrm{~A}(3-19-21)$ & 112.4 & $\mathrm{~A}(3-18-13)$ & 117.0 \\
\hline $\mathrm{A}(11-4-12)$ & 105.3 & $\mathrm{~A}(11-4-12)$ & 105.3 & $\mathrm{~A}(3-18-17)$ & 122.9 \\
\hline $\mathrm{A}(4-11-5)$ & 112.0 & $\mathrm{~A}(4-11-5)$ & 112.0 & $\mathrm{~A}(19-3-38)$ & 112.0 \\
\hline $\mathrm{A}(4-11-9)$ & 128.8 & $A(4-11-9)$ & 128.8 & $\mathrm{~A}(3-19-20)$ & 106.5 \\
\hline $\mathrm{A}(4-12-13)$ & 128.8 & $\mathrm{~A}(4-12-13)$ & 128.8 & $\mathrm{~A}(3-19-21)$ & 112.3 \\
\hline$A(6-5-11)$ & 122.3 & $\mathrm{~A}(6-5-11)$ & 122.3 & $\mathrm{~A}(11-4-12)$ & 105.3 \\
\hline$A(5-6-7)$ & 117.0 & $A(5-6-7)$ & 117.0 & $\mathrm{~A}(4-11-5)$ & 112.0 \\
\hline$A(5-6-32)$ & 122.2 & $A(5-6-32)$ & 122.2 & $A(4-11-9)$ & 128.8 \\
\hline $\mathrm{A}(5-11-9)$ & 119.2 & $\mathrm{~A}(5-11-9)$ & 119.2 & $\mathrm{~A}(4-12-13)$ & 128.8 \\
\hline $\mathrm{A}(7-6-32)$ & 120.8 & $A(7-6-32)$ & 120.8 & $\mathrm{~A}(6-5-11)$ & 122.2 \\
\hline $\mathrm{A}(6-7-8)$ & 121.9 & $\mathrm{~A}(6-7-8)$ & 121.9 & $A(5-6-7)$ & 117.0 \\
\hline $\mathrm{A}(6-7-33)$ & 118.9 & $\mathrm{~A}(6-7-33)$ & 118.9 & $A(5-6-32)$ & 122.2 \\
\hline $\mathrm{A}(8-7-33)$ & 119.2 & $\mathrm{~A}(8-7-33)$ & 119.2 & $A(5-11-9)$ & 119.2 \\
\hline $\mathrm{A}(7-8-9)$ & 121.4 & $\mathrm{~A}(7-8-9)$ & 121.4 & $A(7-6-32)$ & 120.8 \\
\hline $\mathrm{A}(7-8-30)$ & 119.0 & $\mathrm{~A}(7-8-30)$ & 119.0 & $\mathrm{~A}(6-7-8)$ & 121.9 \\
\hline $\mathrm{A}(9-8-30)$ & 119.6 & $\mathrm{~A}(9-8-30)$ & 119.6 & $\mathrm{~A}(6-7-33)$ & 118.9 \\
\hline $\mathrm{A}(8-9-10)$ & 122.1 & $\mathrm{~A}(8-9-10)$ & 122.1 & $\mathrm{~A}(8-7-33)$ & 119.2 \\
\hline $\mathrm{A}(8-9-11)$ & 118.3 & $\mathrm{~A}(8-9-11)$ & 118.3 & $\mathrm{~A}(7-8-9)$ & 121.4 \\
\hline $\mathrm{A}(10-9-11)$ & 119.6 & $\mathrm{~A}(10-9-11)$ & 119.6 & $\mathrm{~A}(7-8-30)$ & 119.0 \\
\hline $\mathrm{A}(12-13-14)$ & 124.0 & $\mathrm{~A}(12-13-14)$ & 124.0 & $\mathrm{~A}(9-8-30)$ & 119.6 \\
\hline $\mathrm{A}(12-13-18)$ & 117.9 & $\mathrm{~A}(12-13-18)$ & 117.9 & $\mathrm{~A}(8-9-10)$ & 122.1 \\
\hline $\mathrm{A}(14-13-18)$ & 118.1 & $\mathrm{~A}(14-13-18)$ & 118.1 & $\mathrm{~A}(8-9-11)$ & 118.3 \\
\hline $\mathrm{A}(13-14-15)$ & 120.1 & $\mathrm{~A}(13-14-15)$ & 120.1 & $\mathrm{~A}(10-9-11)$ & 119.6 \\
\hline $\mathrm{A}(13-14-37)$ & 118.0 & $\mathrm{~A}(13-14-37)$ & 118.0 & $\mathrm{~A}(12-13-14)$ & 124.0 \\
\hline $\mathrm{A}(13-18-17)$ & 119.9 & $\mathrm{~A}(13-18-17)$ & 119.9 & $\mathrm{~A}(12-13-18)$ & 117.8 \\
\hline $\mathrm{A}(15-14-37)$ & 121.8 & $\mathrm{~A}(15-14-37)$ & 121.9 & $\mathrm{~A}(14-13-18)$ & 118.1 \\
\hline $\mathrm{A}(14-15-16)$ & 121.2 & $\mathrm{~A}(14-15-16)$ & 121.1 & $\mathrm{~A}(13-14-15)$ & 120.1 \\
\hline $\mathrm{A}(14-15-35)$ & 119.6 & $\mathrm{~A}(14-15-35)$ & 119.7 & $\mathrm{~A}(13-14-37)$ & 118.0 \\
\hline $\mathrm{A}(16-15-35)$ & 119.2 & $\mathrm{~A}(16-15-35)$ & 119.2 & $\mathrm{~A}(13-18-17)$ & 119.9 \\
\hline $\mathrm{A}(15-16-17)$ & 120.1 & $\mathrm{~A}(15-16-17)$ & 120.1 & $\mathrm{~A}(15-14-37)$ & 121.9 \\
\hline $\mathrm{A}(15-16-31)$ & 120.1 & $\mathrm{~A}(15-16-31)$ & 120.1 & $\mathrm{~A}(14-15-16)$ & 121.1 \\
\hline $\mathrm{A}(17-16-31)$ & 119.8 & $\mathrm{~A}(17-16-31)$ & 119.8 & $\mathrm{~A}(14-15-35)$ & 119.6 \\
\hline $\mathrm{A}(16-17-18)$ & 120.6 & $\mathrm{~A}(16-17-18)$ & 120.6 & $\mathrm{~A}(16-15-35)$ & 119.2 \\
\hline $\mathrm{A}(16-17-34)$ & 120.0 & $\mathrm{~A}(16-17-34)$ & 120.0 & $\mathrm{~A}(15-16-17)$ & 120.1 \\
\hline $\mathrm{A}(18-17-34)$ & 119.4 & $\mathrm{~A}(18-17-34)$ & 119.4 & $\mathrm{~A}(15-16-31)$ & 120.1 \\
\hline $\mathrm{A}(20-19-21)$ & 108.3 & $\mathrm{~A}(20-19-21)$ & 108.0 & $\mathrm{~A}(17-16-31)$ & 119.8 \\
\hline $\mathrm{A}(19-21-22)$ & 118.3 & $\mathrm{~A}(19-21-22)$ & 118.3 & $\mathrm{~A}(16-17-18)$ & 120.6 \\
\hline $\mathrm{A}(19-21-26)$ & 123.6 & $\mathrm{~A}(19-21-26)$ & 123.0 & $\mathrm{~A}(16-17-34)$ & 120.0 \\
\hline $\mathrm{A}(22-21-26)$ & 118.1 & $\mathrm{~A}(22-21-26)$ & 118.7 & $\mathrm{~A}(18-17-34)$ & 119.4 \\
\hline $\mathrm{A}(21-22-23)$ & 121.3 & $\mathrm{~A}(21-22-23)$ & 120.9 & $\mathrm{~A}(20-19-21)$ & 108.1 \\
\hline $\mathrm{A}(21-26-25)$ & 121.2 & $\mathrm{~A}(21-26-25)$ & 120.3 & $\mathrm{~A}(19-21-22)$ & 118.1 \\
\hline $\mathrm{A}(21-26-28)$ & 119.2 & $\mathrm{~A}(21-26-28)$ & 119.8 & $\mathrm{~A}(19-21-26)$ & 123.2 \\
\hline $\mathrm{A}(22-23-24)$ & 119.6 & $\mathrm{~A}(22-23-24)$ & 119.9 & $\mathrm{~A}(22-21-26)$ & 118.7 \\
\hline $\mathrm{A}(22-23-29)$ & 120.0 & $\mathrm{~A}(22-23-29)$ & 120.2 & $\mathrm{~A}(21-22-23)$ & 120.5 \\
\hline $\mathrm{A}(24-23-29)$ & 120.5 & $\mathrm{~A}(24-23-29)$ & 119.9 & $\mathrm{~A}(21-26-25)$ & 121.1 \\
\hline $\mathrm{A}(23-24-25)$ & 120.1 & $\mathrm{~A}(23-24-25)$ & 119.3 & $\mathrm{~A}(21-26-28)$ & 120.6 \\
\hline $\mathrm{A}(23-24-27)$ & 119.5 & $\mathrm{~A}(23-24-27)$ & 120.3 & $\mathrm{~A}(22-23-24)$ & 120.5 \\
\hline $\mathrm{A}(25-24-27)$ & 120.4 & $\mathrm{~A}(25-24-27)$ & 120.5 & $\mathrm{~A}(22-23-29)$ & 120.1 \\
\hline $\mathrm{A}(24-25-26)$ & 119.7 & $\mathrm{~A}(24-25-26)$ & 120.9 & $\mathrm{~A}(24-23-29)$ & 119.5 \\
\hline $\mathrm{A}(24-25-39)$ & 120.4 & $\mathrm{~A}(24-25-39)$ & 119.7 & $\mathrm{~A}(23-24-25)$ & 119.5 \\
\hline $\mathrm{A}(26-25-39)$ & 119.9 & $\mathrm{~A}(26-25-39)$ & 119.3 & $\mathrm{~A}(23-24-27)$ & 119.1 \\
\hline \multirow[t]{12}{*}{$\mathrm{A}(25-26-28)$} & 119.6 & $\mathrm{~A}(25-26-28)$ & 119.9 & $\mathrm{~A}(25-24-27)$ & 121.5 \\
\hline & & & & $\mathrm{A}(24-25-26)$ & 119.7 \\
\hline & & & & $\mathrm{A}(24-25-39)$ & 124.8 \\
\hline & & & & $\mathrm{A}(26-25-39)$ & 115.5 \\
\hline & & & & $\mathrm{A}(25-26-28)$ & 118.2 \\
\hline & & & & $\mathrm{A}(25-39-40)$ & 118.4 \\
\hline & & & & $\mathrm{A}(39-40-41)$ & 105.8 \\
\hline & & & & $\mathrm{A}(39-40-42)$ & 111.4 \\
\hline & & & & $\mathrm{A}(39-40-43)$ & 111.4 \\
\hline & & & & $\mathrm{A}(41-40-42)$ & 109.3 \\
\hline & & & & $\mathrm{A}(41-40-43)$ & 109.3 \\
\hline & & & & $\mathrm{A}(42-40-43)$ & 109.5 \\
\hline
\end{tabular}

comparison data between the bond length and bond angles of the all three compounds; $\mathbf{L}-\mathbf{H}, \mathbf{L}-\mathbf{B r}$ and $\mathbf{L}-\mathbf{O C H}_{3}$. Most of these values showed good agreement except for those involving the substituent which may suggest that the effect of substituent is localized. The bond length, $\mathrm{R}(25-39)$ have values of 1.085 $\AA, 1.368 \AA$ and $1.904 \AA$ for C-H, C-O and C-Br, respectively. The bond angles $\mathrm{A}(24-25-39)$ have values of $120.4^{\circ}, 124.8^{\circ}$ and $119.7^{\circ}$ for C-C-H, C-C-O and C-C-Br, respectively. The bond angles $\mathrm{A}(26-25-39)$ have values of $119.9^{\circ}, 115.5^{\circ}$ and $119.4^{\circ}$ for C-C-H, C-C-O and C-C-Br, respectively.

The singlet optimized excited state geometry of the three compounds, L-H, L-Br and $\mathbf{L}-\mathbf{O C H}_{3}$ were calculated using TD-DFT B3LYP with 6-31++G(d,p) basis set. The geometry of the $\mathbf{L - B r}$ optimized excited state is shown in Fig. 2. The TD-DFT calculations yield comparable values with that of optimized ground state geometry. The optimized ground and optimized excited state bond lengths and bond angles values are very close to each other (Figs. 3 and 4) except for the bonds $\mathrm{R}$ (4-12) and R (12-13) which are longer in excited state by a factor of about $5 \%$. This may suggest that the geometries of $\mathbf{L - H}, \mathbf{L - B r}$ and $\mathbf{L}-\mathbf{O C H}_{3}$ are rigid which is believed to directly affect the life-time and internal conversion in OLED devices. The rigidity of the backbone is required for harvesting high quantum yield emission in OLED [15].

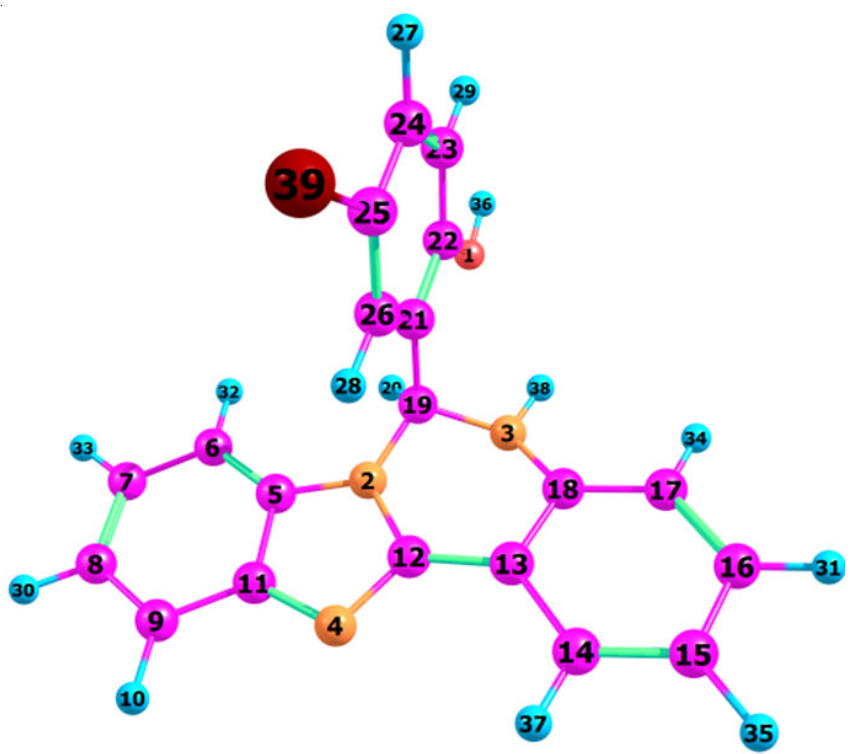

Fig. 2. Optimized excited state geometry of compound $\mathbf{L - B r}$

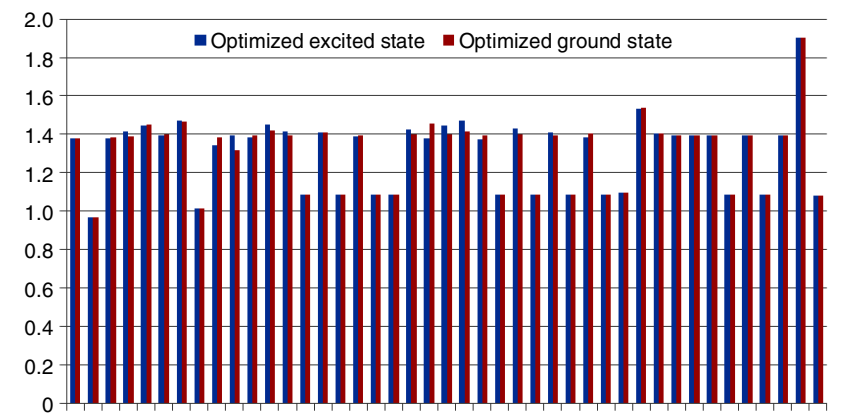

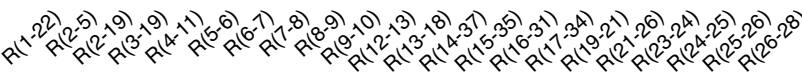

Fig. 3. Comparison between optimized ground and optimized excited state bond lengths of compound $\mathbf{L}-\mathbf{B r}$ 


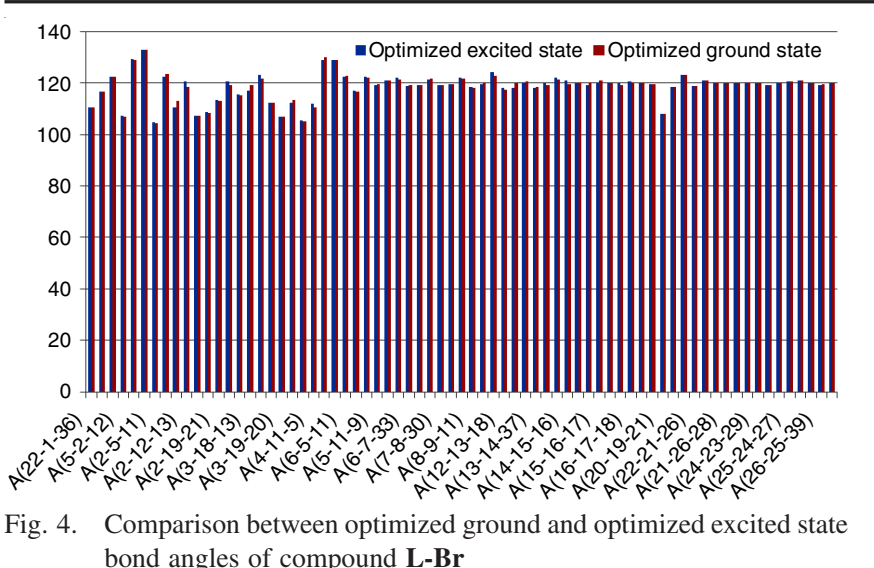

Molecular orbital analysis: Frontier molecular orbitals especially HOMO and LUMO and their energies are important parameters in determining the chemical stability, atomic interactions, optical properties, biological activities and molecular electrical transport properties of molecules [16]. Fig. 5 shows that the electron density of the HOMO and LUMO molecular orbitals in $\mathbf{L - H}, \mathbf{L - B r}$ and $\mathbf{L}-\mathbf{O C H}_{3}$. In the three compounds the HOMO and LUMO orbitals were mainly delocalized over the whole molecule except on phenol ring which is electrondeficient in both HOMO and LUMO. HOMO showed $\pi$-bonding character over whole molecule, whereas LUMO showed $\pi *$-antibonding character, except on phenol ring.

Electronic spectral analysis: The electronic absorption bands were calculated using TD-DFT at B3LYP/6-31++G(d,p) level of theory. The calculated absorption wavelengths $\left(\lambda_{\max }\right)$, oscillator strength and molecular orbitals contribution are given in Table-3. In the electronic absorption spectrum of $\mathbf{L}-\mathbf{H}, \mathbf{L}-\mathbf{B r}$ and $\mathbf{L}-\mathbf{O C H}_{3}$, there are two absorption bands with a maximum
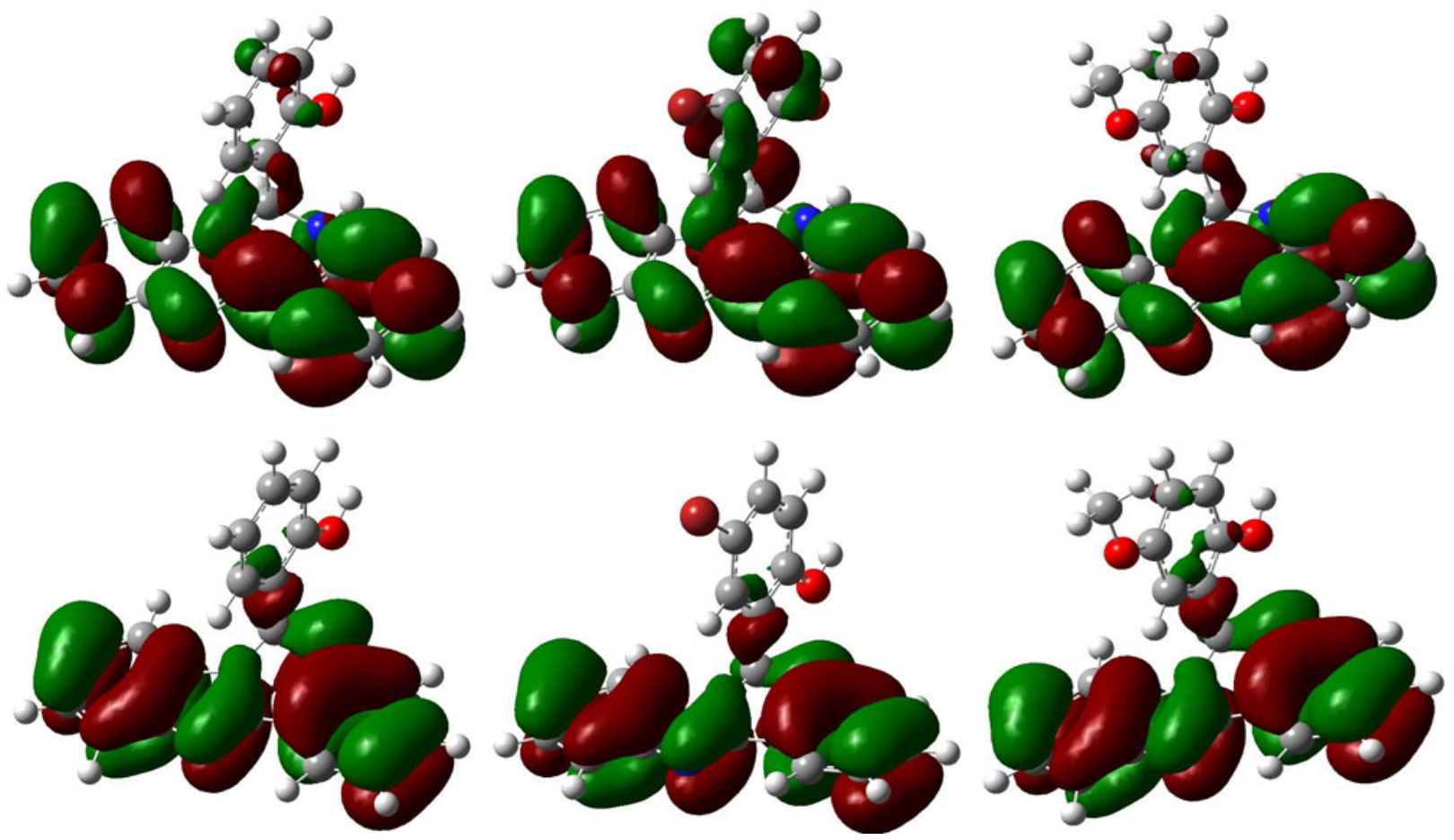

Fig. 5. HOMO and LUMO molecular orbital shapes of $\mathbf{L}-\mathbf{H}, \mathbf{L}-\mathbf{B r}$ and $\mathbf{L}-\mathbf{O C H}_{3}$ using B3LYP/6-31++G(d,p)

TABLE-3

SINGLET STATE TRANSITIONS FOR L-H, L-Br AND L-OCH 3 MOLECULES CALCULATED USING TD-DFT METHOD WITH THEIR OSCILLATOR STRENGTH AND THEIR MAJOR ORBITAL CONTRIBUTIONS IN GAS PHASE

\begin{tabular}{|c|c|c|c|}
\hline & Wavelength (nm) & Osc. Strength & Major orbital contribution \\
\hline \multirow[b]{2}{*}{ L-H } & 334 & 0.2486 & $\begin{array}{l}\mathrm{HOMO}(\mathrm{A}) \rightarrow \mathrm{LUMO}(\mathrm{A})(45 \%), \mathrm{HOMO}(\mathrm{B}) \rightarrow \mathrm{LUMO}(\mathrm{B})(45 \%), \mathrm{H}-1(\mathrm{~A}) \rightarrow \mathrm{LUMO}(\mathrm{A})(2 \\
\%), \mathrm{H}-1(\mathrm{~B}) \rightarrow \mathrm{LUMO}(\mathrm{B})(2 \%)\end{array}$ \\
\hline & 285 & 0.207 & $\begin{array}{l}\mathrm{H}-1(\mathrm{~A}) \rightarrow \mathrm{LUMO}(\mathrm{A})(38 \%), \mathrm{H}-1(\mathrm{~B}) \rightarrow \mathrm{LUMO}(\mathrm{B})(38 \%) \mathrm{HOMO}(\mathrm{A}) \rightarrow \operatorname{LUMO}(\mathrm{A})(3 \%), \\
\mathrm{HOMO}(\mathrm{A}) \rightarrow \mathrm{L}+2(\mathrm{~A})(4 \%), \mathrm{HOMO}(\mathrm{A}) \rightarrow \mathrm{L}+4(\mathrm{~A})(2 \%), \mathrm{HOMO}(\mathrm{B}) \rightarrow \operatorname{LUMO}(\mathrm{B})(3 \%) \\
\mathrm{HOMO}(\mathrm{B}) \rightarrow \mathrm{L}+2(\mathrm{~B})(4 \%), \mathrm{HOMO}(\mathrm{B}) \rightarrow \mathrm{L}+4(\mathrm{~B})(2 \%)\end{array}$ \\
\hline \multirow{3}{*}{ L-Br } & 335 & 0.1885 & $\begin{array}{l}\mathrm{HOMO}(\mathrm{A}) \rightarrow \mathrm{LUMO}(\mathrm{A})(43 \%), \mathrm{HOMO}(\mathrm{B}) \rightarrow \mathrm{LUMO}(\mathrm{B})(43 \%), \mathrm{H}-1(\mathrm{~A}) \rightarrow \mathrm{LUMO}(\mathrm{A})(2 \\
\%), \mathrm{HOMO}(\mathrm{A}) \rightarrow \mathrm{L}+1(\mathrm{~A})(3 \%), \mathrm{H}-1(\mathrm{~B}) \rightarrow \mathrm{LUMO}(\mathrm{B})(2 \%), \mathrm{HOMO}(\mathrm{B}) \rightarrow \mathrm{L}+1(\mathrm{~B})(3 \%)\end{array}$ \\
\hline & 319 & 0.087 & $\begin{array}{l}\mathrm{HOMO}(\mathrm{A}) \rightarrow \mathrm{L}+1(\mathrm{~A})(45 \%), \mathrm{HOMO}(\mathrm{B}) \rightarrow \mathrm{L}+1(\mathrm{~B})(45 \%) \mathrm{HOMO}(\mathrm{A}) \rightarrow \mathrm{LUMO}(\mathrm{A})(2 \%), \\
\mathrm{HOMO}(\mathrm{B}) \rightarrow \mathrm{LUMO}(\mathrm{B})(2 \%)\end{array}$ \\
\hline & 287 & 0.1663 & $\begin{array}{l}\mathrm{H}-1(\mathrm{~A}) \rightarrow \mathrm{LUMO}(\mathrm{A})(41 \%), \mathrm{H}-1(\mathrm{~B}) \rightarrow \mathrm{LUMO}(\mathrm{B})(41 \%) \mathrm{HOMO}(\mathrm{A}) \rightarrow \operatorname{LUMO}(\mathrm{A})(3 \%) \\
\mathrm{HOMO}(\mathrm{B}) \rightarrow \mathrm{LUMO}(\mathrm{B})(3 \%)\end{array}$ \\
\hline \multirow[b]{2}{*}{$\mathrm{L}-\mathrm{OCH}_{3}$} & 334 & 0.2462 & $\mathrm{HOMO}(\mathrm{A}) \rightarrow \mathrm{LUMO}(\mathrm{A})(45 \%), \mathrm{HOMO}(\mathrm{B}) \rightarrow \mathrm{LUMO}(\mathrm{B})(45 \%)$ \\
\hline & 284 & 0.1552 & $\begin{array}{l}\mathrm{H}-2(\mathrm{~A}) \rightarrow \mathrm{LUMO}(\mathrm{A})(38 \%), \mathrm{H}-2(\mathrm{~B}) \rightarrow \mathrm{LUMO}(\mathrm{B})(38 \%), \mathrm{H}-1(\mathrm{~A}) \rightarrow \mathrm{LUMO}(\mathrm{A})(4 \%), \\
\mathrm{HOMO}(\mathrm{A}) \rightarrow \mathrm{LUMO}(\mathrm{A})(3 \%), \mathrm{H}-1(\mathrm{~B}) \rightarrow \mathrm{LUMO}(\mathrm{B})(4 \%), \mathrm{HOMO}(\mathrm{B}) \rightarrow \mathrm{LUMO}(\mathrm{B})(3 \%)\end{array}$ \\
\hline
\end{tabular}


of $335 \mathrm{~nm}$ as shown in Fig. 6. The strong absorption band at $335 \mathrm{~nm}$ is caused by the $\pi \rightarrow \pi^{*}$, where the major contribution of this band comes from HOMO $\rightarrow$ LUMO $(90 \%)$ and the other less intensive band is due to $n \rightarrow \pi^{*}$ transitions [17], the major contribution of this band comes from HOMO- $1 \rightarrow$ LUMO (76 \%). The HOMO and LUMO of $\mathbf{L}-\mathbf{H}, \mathbf{L}-\mathbf{B r}$ and $\mathbf{L}-\mathbf{O C H}_{3}$ are represented in Fig. 5.

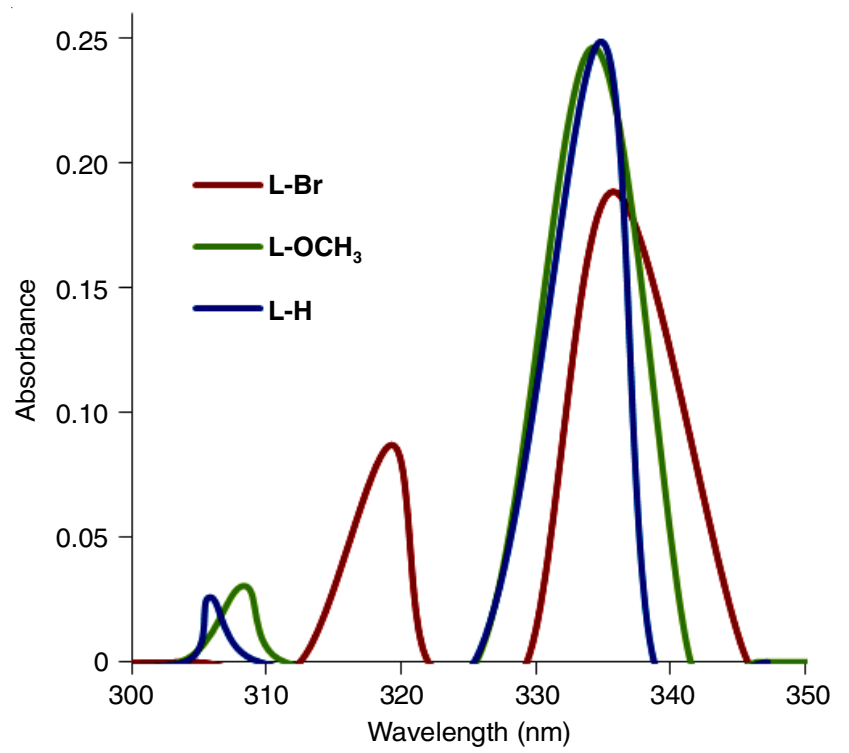

Fig. 6. Electronic spectra of $\mathbf{L - H}, \mathbf{L - B r}$ and $\mathbf{L}-\mathbf{O C H} \mathbf{C H}_{3}$ in gas phase

Molecular electrostatic potential: Molecular electrostatic potential (MEP) can be used to predict the polarization, electron correlation and charge transfer effect and the chemical reactivity of a molecule [18]. The MEP is especially important for the identification of the reactive positions of nucleophilic or electrophilic attack, to study hydrogen-bonding interactions and for the understanding of the process of biological recognition [19]. For OLED applications MEP is useful to study the geometry interactions between the host and the dopant, consequently, the possible binding sites can be found by look over the partial charge distributions on the molecular geometries of the host and dopant molecule [20]. The surfaces of $\mathbf{L}-\mathbf{H}, \mathbf{L}-\mathbf{B r}$ and $\mathbf{L}-\mathbf{O C H}_{3}$ were plotted over an optimized electronic structure using B3LYP/6-31++G(d,p) as shown in Fig. 7.

The most positive (blue) regions are localized on hydrogen atoms of hydroxyl groups, showing electrophilic reactivity; whereas the most negative (red) regions are observed around the nitrogen atoms. Also, relative negative regions (yellow) are observed around aromatic carbon atoms of the phenyl ring showing nucleophilic reactivity. From these results, we can conclude that the $\mathrm{H}$ atoms of hydroxyl groups represent the strongest attraction and $\mathrm{N}$ atom indicates the strongest repulsion [18]. This would be useful in optimizing the multilayerOLED devises by choosing the suitable hole transport, emissive and electron transport layers.

Charge transport property: Table-4 shows the reorganization energies of the hole and electron, the adiabatic ionization potential $\left(\mathrm{IP}_{\mathrm{a}}\right)$, adiabatic electron affinity $\left(\mathrm{EA}_{\mathrm{a}}\right)$, vertical ionization potential $\left(\mathrm{IP}_{\mathrm{v}}\right)$ and vertical electron affinity $\left(\mathrm{EA}_{\mathrm{v}}\right)$ for $\mathbf{L}-\mathbf{H}, \mathbf{L}-\mathbf{B r}$ and $\mathbf{L}-\mathbf{O C H}_{3}$. The reorganization energy is inversely related to the charge transfer rate $[21,22]$. The reorganization energies calculated for hole $\lambda_{\mathrm{h}}$ of $\mathbf{L}-\mathbf{H}, \mathbf{L}-\mathbf{B r}$ and $\mathbf{L - O C H}$ are about $20 \%$ higher than that of N,N'-diphenyl$\mathrm{N}, \mathrm{N}^{\prime}$-bis(3-methlphenyl)-(1,1'-biphenyl)-4,4'-diamine (DPDA) which is a good hole transport material with $\lambda_{\mathrm{h}}=0.290 \mathrm{eV}$ [23]. This may suggest that the hole transfer rates of $\mathbf{L}-\mathbf{H}, \mathbf{L}-$ $\mathrm{Br}$ and $\mathbf{L}-\mathbf{O C H}_{3}$ are lower than that of DPDA. The reorganization energies calculated for electron $\lambda_{\mathrm{e}}$ values of $\mathbf{L}-\mathbf{H}, \mathbf{L}-\mathbf{B r}$

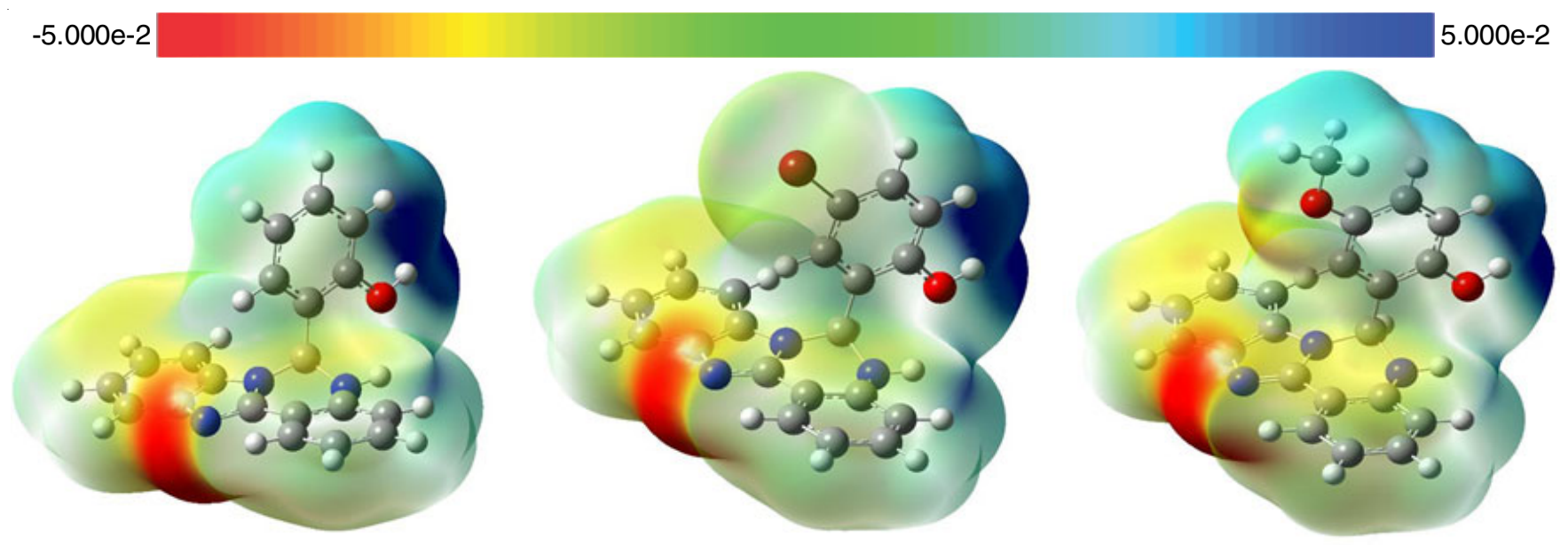

Fig. 7. Colour code of the map represents the range from $-5.0 \times 10^{-2} \mathrm{eV}$ (deepest red) to $5.0 \times 10^{-2} \mathrm{eV}$ (deepest blue)

TABLE-4

CALCULATED MOLECULAR $\lambda_{e}, \lambda_{k}$, ADIABATIC IONIZATION POTENTIAL (IP), ADIABATIC ELECTRON AFFINITY (EA A $_{a}$, VERTICAL IONIZATION POTENTIAL (IPv) AND VERTICAL ELECTRON AFFINITY $\left(\mathrm{EA}_{\mathrm{v}}\right)$ (ALL IN eV) OF L-H, L-Br AND L-OCH 3 AT THE B3LYP/6-31++G(d,p) LEVEL

\begin{tabular}{|c|c|c|c|c|c|c|c|}
\hline Compound & $\lambda_{\mathrm{e}}$ & $\lambda_{\mathrm{h}}$ & $\Delta \lambda$ & $\mathrm{IP}_{\mathrm{a}}$ & $\mathrm{EA}_{\mathrm{a}}$ & $\mathrm{IP}_{\mathrm{v}}$ & $\mathrm{EA}_{\mathrm{v}}$ \\
\hline L-H & 0.1408 & 0.3778 & 0.2370 & 0.2495 & 0.0068 & 0.2568 & 0.0044 \\
\hline L-Br & 0.1289 & 0.3786 & 0.2498 & 0.2526 & 0.0108 & 0.2598 & 0.0087 \\
\hline $\mathrm{L}-O C H_{3}$ & 0.1350 & 0.3623 & 0.2274 & 0.2466 & 0.0054 & 0.2536 & 0.0032 \\
\hline
\end{tabular}



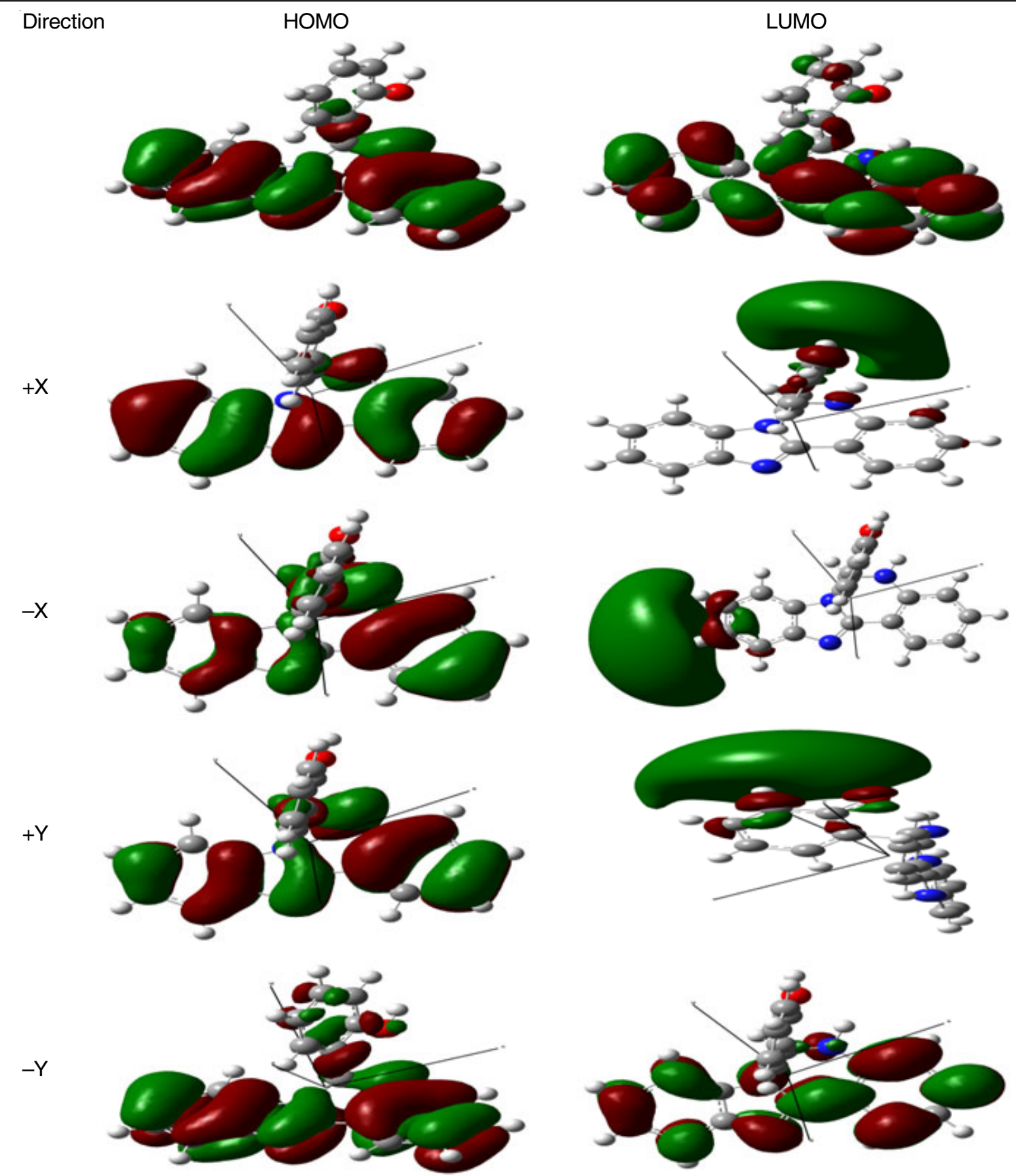

$+Z$
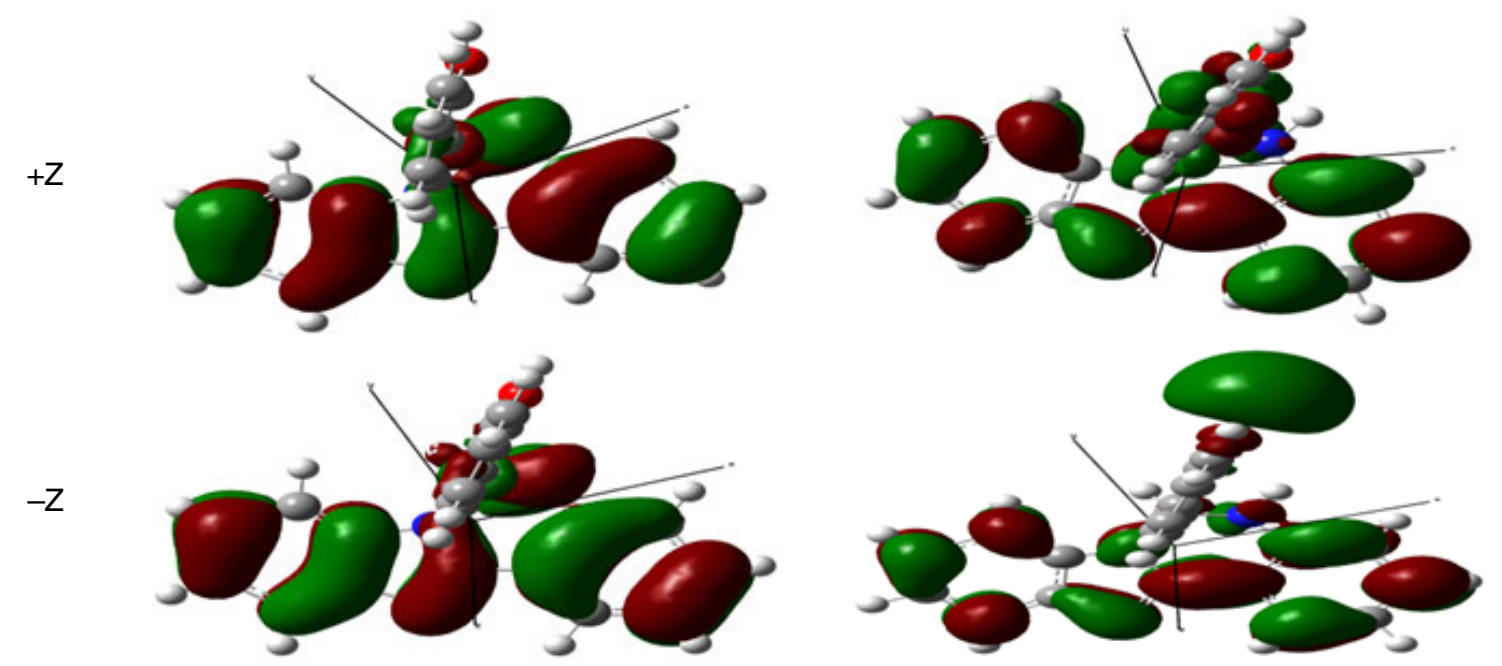

Fig. 8. HOMO and LUMO spatial distribution under (0.3 V/Å) electric fields 
and $\mathbf{L - O C H}$ are about $50 \%$ smaller than that of tris(8-hydroxyquinolinato)aluminum(III) (Alq3), which is a good electron transport material with $\lambda_{\mathrm{e}}=0.276 \mathrm{eV}$ [24]. This suggests that our studied compounds electron transfer rates might be higher than that of Alq3. The $\lambda_{\mathrm{e}}$ values of $\mathbf{L}-\mathbf{H}, \mathbf{L}-\mathbf{B r}$ and $\mathbf{L}-\mathbf{O C H} \mathbf{C H}_{3}$ are lower than those of their $\lambda_{h}$ values, indicating that the carrier mobility of the electron is larger than that of the hole. In conclusion, $\mathbf{L}-\mathbf{H}, \mathbf{L - B r}$ and $\mathbf{L}-\mathbf{O C} \mathbf{H}_{3}$ can be used as promising electron transport materials in the OLEDs from the stand point of the smaller reorganization energy. The difference in reorganization energy of hole/electron is higher in bromidesubstituted compound L-Br (0.2498) comparing with unsubstituted L-H (0.2370) and methoxy group substituted compound $\mathbf{L}-\mathbf{O C H}_{3}(0.2274)$. It is concluded that the substitution with electron withdrawing bromide atom, $\Delta \mathrm{E}$ value slightly increases. Also, with the substitution of electron donating methoxy group, $\Delta \mathrm{E}$ value slightly decreases. This can be used to tune the hole/ electron reorganization energies.

Influence of electric field on the electronic structure of 2-(5,6-dihydrobenzimidazo[1,2-c]quinazolin-6-yl)phenol (L-H): The L-H molecule was successfully optimized in the $\pm \mathrm{X}, \pm \mathrm{Y}$ and $\pm \mathrm{Z}$ direction under applied uniform current field of 3.0 V/Å. The applied current field in all direction showed changing in molecular orbital distribution especially for LUMO and it causes changing in the dipole moment. However, the highest effect with respect to dipole moment was observed in the $-\mathrm{X}$ direction, which is used as indicator for possible direction of charge transfer. In general, the molecules exhibited large dipole moment have strong asymmetry in the distribution of electronic charge, consequently, they can be sensitive to any change in the electronic structure and electronic properties under an external electric field [25].

The HOMO and LUMO spatial distribution is vital for the description of transport properties because they predominate the coupling of the molecular bridge [13]. The HOMO and LUMO spatial distribution in the $\pm \mathrm{X}, \pm \mathrm{Y}$ and $\pm \mathrm{Z}$ direction under applied uniform current field of $3.0 \mathrm{~V} / \AA ̊$ has been illustrated in Fig. 8. It has been observed that under electric field in $\pm \mathrm{X}, \pm \mathrm{Y}$ and $\pm \mathrm{Z}$ direction, the HOMO is less affected comparing with the LUMO. For HOMO the presence and absence of electric field showed unobservable effect except in $\pm X$ direction. Applying the electric filed in the $-\mathrm{X}$ direction cause the movement of electron density from left side of molecule to the right side, in the $+\mathrm{X}$ direction, the movement of electron density in the opposite direction is observed. Appling electric field in $-Y,+Z$ directions has less effect on the LUMO, in $+X$ and $+\mathrm{Y}$ directions the electron density is localized on the phenol ring. In the $-\mathrm{X}$ direction the electron density is localized on the left-side of the benzene ring. Finally, in $-\mathrm{Z}$ direction $\pi^{*}$ the anti-bonding character with high electron density is localized on the phenol ring.

The molecule $(\mathrm{L}-\mathrm{H})$ contains a number of p-electrons delocalized over the whole molecule except the phenol ring. The electric field will affect both the charge distribution and geometry of the molecule. In a given molecule the electric field alters the charge distributions. It then changes the geometrical factors of the molecule [13] therefore, it is important to study the influence of electric field on the geometrical parameters.
We studied the influence of electric field direction $\pm X$, $\pm \mathrm{Y}$ and $\pm \mathrm{Z}$ on each bond length and bond angle of the molecule. Fig. 9 shows the deviation (\%) of the bond length and bond angle of the molecule in $+\mathrm{X}$ and $-\mathrm{X}$ directions in presence and in absence of electric fields, for $\pm Y$ and $\pm Z$.

The most interesting results from Fig. 9 is elongation of the bond $\mathrm{R}(1-22)$ for about $0.4 \%$ when applied the electric filed in $+\mathrm{X}$ direction. This bond becomes shorter when we inverse the electric filed direction to the-X. The same observation was noticed to several bond length and bonds angles as show in Fig. 9.

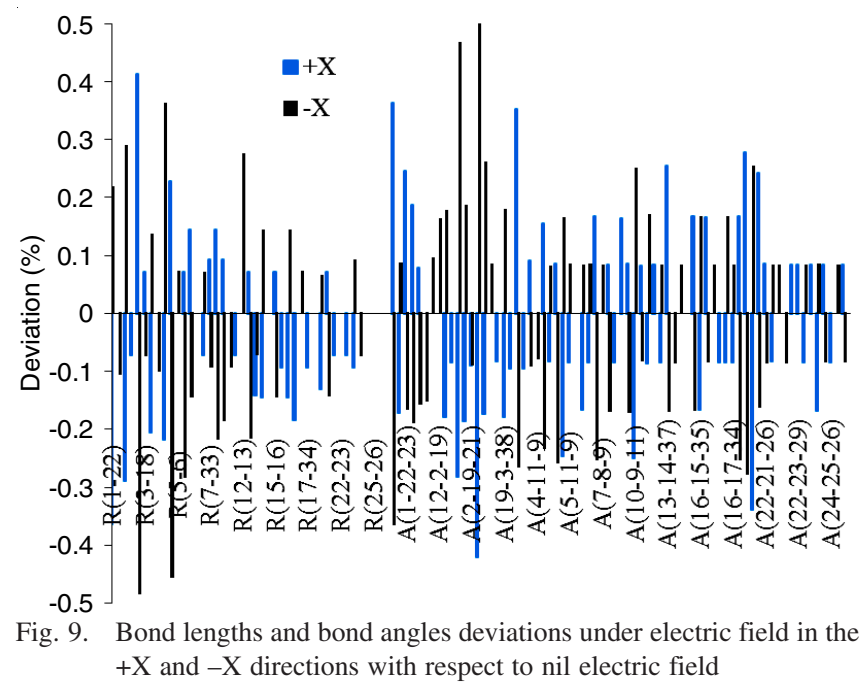

Fig. 10 shows the HOMO and LUMO spatial distribution under different electric fields. It is noticed that the increase of electric field has a big effect on the LUMO than on the HOMO. The HOMO conserves the delocalization of electron density over the whole molecule with reducing the electron density on the left side of the molecule as the electric field increases. In the other hand, the LUMO maintains the $\pi$-antibonding character which is delocalized over the whole molecule with slight electron distribution change up to $0.25 \mathrm{~V} / \AA$ then the molecule undergoes dramatic change and the electron densities localized at the end of left side of the molecule. It is concluded that as an electric field increases the electron densities reduce in HOMO and increase in LUMO. Also, LUMO is more sensitive for increasing electric filed, as supported also by the change in HOMO-LUMO energies (Fig. 11).

The total dipole moment calculation showed that charge distribution is asymmetric in $\mathbf{L - H}$ molecule. Consequently, the electric field displaces the nucleus in the electric field direction and therefore, the electrons are rearranged [13].

Fig. 12 shows the linear relation between the dipole moment and strength of electric field in X-direction, this result could be used to improve the OLED devices through orientation of the molecules In spite of a few studies have been done on this field but it is proved that the molecular orientation of OLED materials is significant on performance of both optical and electrical devices [26].

\section{Conclusion}

Density functional theory (DFT) at the B3LYP/6-31++G(d,p) level of theory was used to optimized the geometries of the $\mathbf{L}-\mathbf{H}, \mathbf{L - B r}$ and $\mathbf{L}-\mathbf{O C H}_{3}$ molecules. The theoretical vibrational 


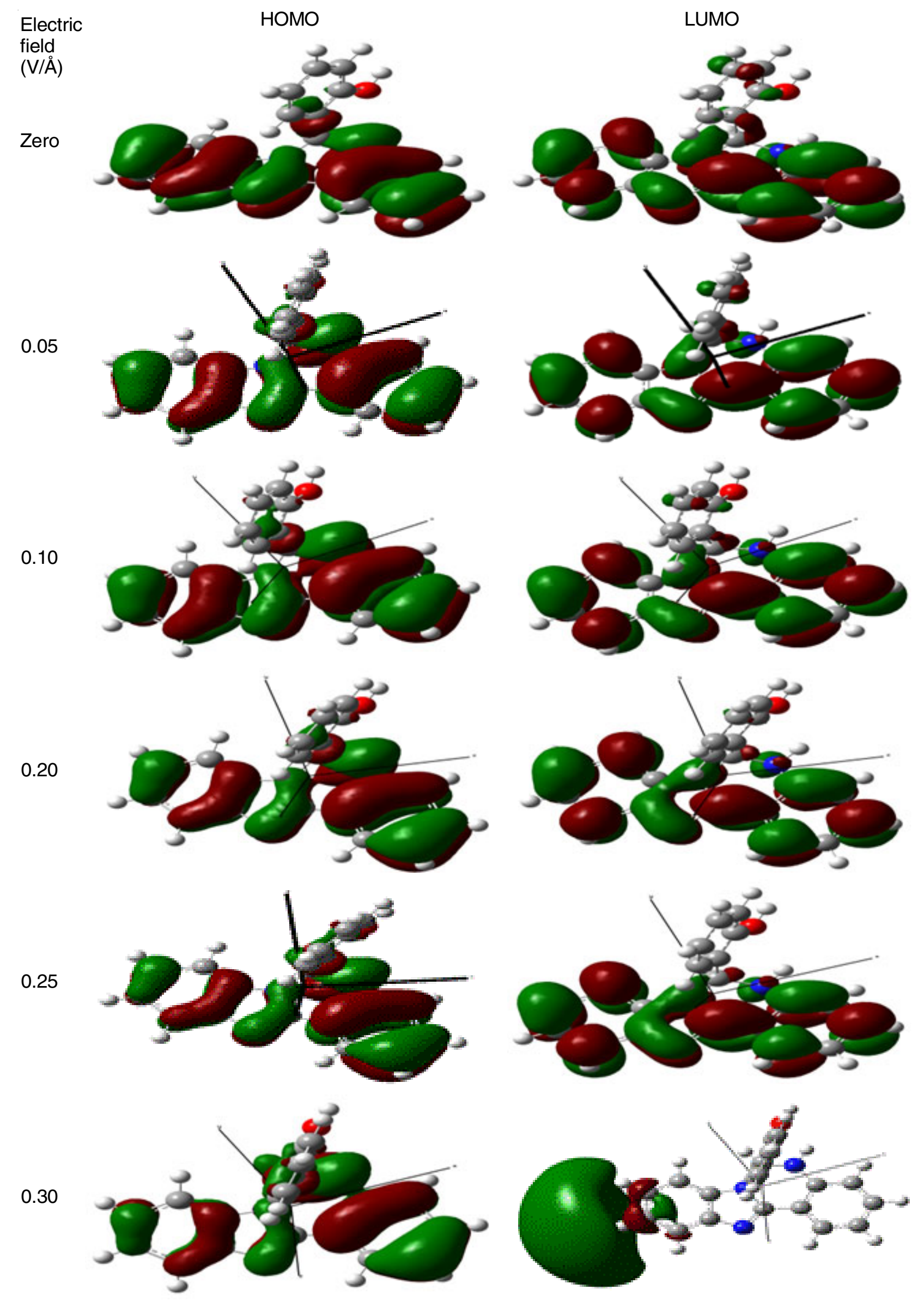

Fig. 10. HOMO and LUMO spatial distribution under different electric fields 


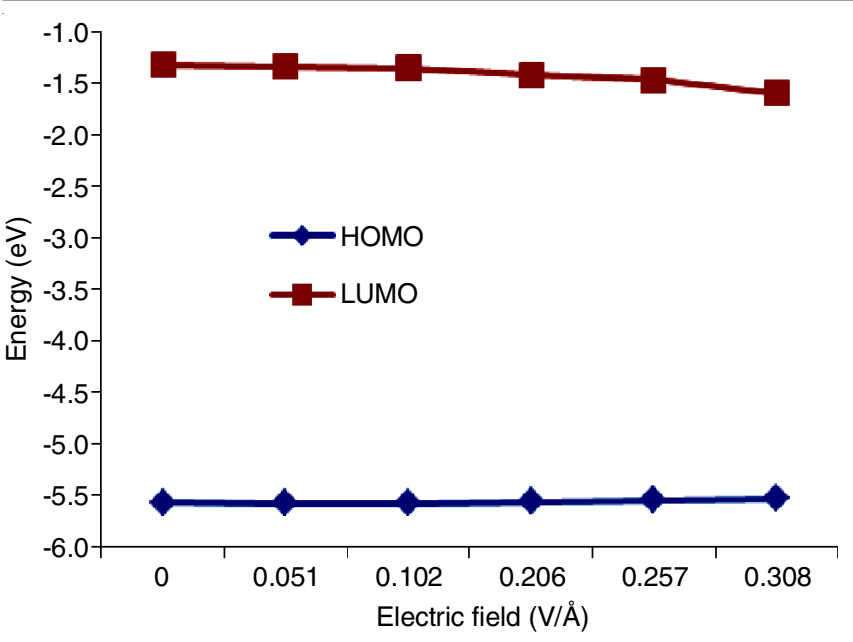

Fig. 11. Influence of electric filed strength on HOMO, LUMO energies

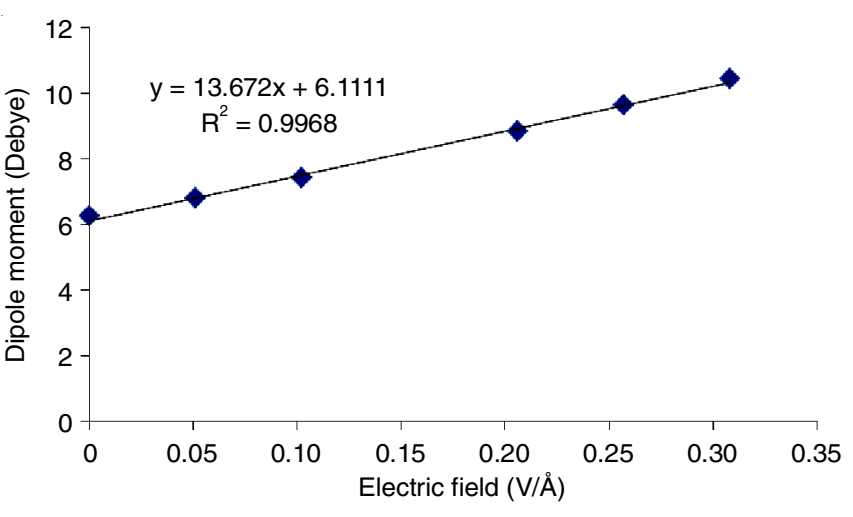

Fig. 12. Influence of electric filed strength on the total dipole moment

frequencies obtained by DFT calculations confirmed the global minima (Table-5). The electronic structures were described in

\begin{tabular}{|c|c|c|c|c|}
\hline \multicolumn{5}{|c|}{$\begin{array}{l}\text { TABLE-5 } \\
\text { COMPUTATIONAL CALCULATED VIBRATIONAL WAVENUMBERS [HARMONIC FREQUENCY }\left(\mathrm{cm}^{-1}\right) \text { ], } \\
\text { ASSIGNMENTS AND CONTRIBUTION FOR L-Br AT DFT/B3LYP UTILIZING 6-31G++(d,p) BASIS SETS }\end{array}$} \\
\hline IR & $\mathrm{cm}^{-1}$ & & & \\
\hline 3832.30 & $v \mathrm{OH} 100$ & & & \\
\hline 3607.21 & $v$ NH 100 & & & \\
\hline 3230.96 & v $\mathrm{CH} 99$ & & & \\
\hline 3224.72 & v CH 97 & & & \\
\hline 3218.12 & $\vee \mathrm{CH} 70$ & v CH 26 & & \\
\hline 3213.00 & v $\mathrm{CH} 22$ & v CH 64 & & \\
\hline 3204.73 & v CH -32 & $v \mathrm{CH}-41$ & v CH 22 & \\
\hline 3204.43 & $v \mathrm{CH}-26$ & v CH 39 & $v \mathrm{CH} 30$ & \\
\hline 3193.43 & $\vee \mathrm{CH}-46$ & v CH 39 & & \\
\hline 3191.29 & $v \mathrm{CH}-32$ & v $\mathrm{CH} 44$ & v CH 21 & \\
\hline 3183.31 & $v \mathrm{CH}-17$ & $v \mathrm{CH} 43$ & $v \mathrm{CH}-36$ & \\
\hline 3174.82 & $v \mathrm{CH}-22$ & $v \mathrm{CH} 75$ & & \\
\hline 3174.54 & v $\mathrm{CH} 96$ & & & \\
\hline 3073.01 & $v \mathrm{CH} 100$ & & & \\
\hline 1663.26 & $v \mathrm{CC}-16$ & $v$ CC 10 & $v \mathrm{CC}-16 \quad v \mathrm{CC} \quad 14$ & \\
\hline 1660.43 & $v \mathrm{CC} 10$ & $v$ CC -20 & $v$ CC 21 & \\
\hline 1648.43 & $v \mathrm{CC} 36$ & & & \\
\hline 1633.97 & $v$ CC 28 & $v \mathrm{CC}-18$ & $\beta$ CCC $13 \beta$ CCC -10 & \\
\hline 1626.44 & $v$ CC 32 & & & \\
\hline 1624.31 & $\beta$ CCC 11 & $\beta \mathrm{CNC} 12$ & $\beta$ CCC $12 \beta$ CNC 10 & \\
\hline 1577.39 & $v \mathrm{NC}-21$ & $v$ CC 21 & $\beta$ NCN 10 & \\
\hline 1531.78 & $v \mathrm{NC}-10$ & $\beta$ HNC 23 & & \\
\hline 1520.19 & $\beta$ HCC -14 & $\beta$ HCC -20 & & \\
\hline 1517.13 & $v$ CC -20 & $\beta$ HCC 18 & $\beta$ HCC 18 & \\
\hline 1514.21 & $\beta$ HCC -17 & $\beta$ HCC 21 & & \\
\hline 1480.19 & $\beta$ HCC 17 & $\beta$ HCC -18 & $\beta \mathrm{CNC} 11$ & \\
\hline 1475.40 & $\beta$ HNC 17 & $\beta$ HCC 10 & $\tau \mathrm{HCCC}-11$ & \\
\hline 1445.90 & $v$ CC 19 & $v \mathrm{CC}-13$ & $v$ CC $10 \quad \beta$ HCC 12 & $\beta \mathrm{HCC}-10$ \\
\hline 1418.98 & $v$ NC 15 & $\tau \mathrm{HCCC}-14$ & & \\
\hline 1402.80 & $v$ NC 21 & $\beta$ HCC 10 & & \\
\hline 1379.58 & & & & \\
\hline 1373.16 & $\beta$ HCC 43 & & & \\
\hline 1360.52 & $v$ CC -14 & $v$ CC 13 & $\beta \mathrm{HOC}-12$ & \\
\hline 1348.47 & $\beta$ HCC -22 & & & \\
\hline 1325.37 & $\beta$ HCC 13 & $\beta$ HCC 15 & $\beta$ HCC 15 & \\
\hline 1306.86 & $\beta$ HCC 18 & & & \\
\hline 1305.71 & $\beta$ HCC -13 & $\tau$ HCCC 11 & & \\
\hline 1293.42 & $v$ NC 17 & & & \\
\hline 1280.07 & $v$ NC 20 & $\tau$ HCCC -11 & & \\
\hline 1266.14 & $v$ OC 24 & & & \\
\hline
\end{tabular}




\begin{tabular}{|c|c|c|c|}
\hline 1263.47 & $v \mathrm{NC} 10$ & $\beta \mathrm{HCC}-10$ & \\
\hline 1208.13 & & & \\
\hline 1192.08 & $v$ CC -10 & $\beta$ HOC 27 & \\
\hline 1184.88 & $v$ CC 11 & $\beta$ HOC 14 & $\beta$ HCC $27 \beta$ HCC 26 \\
\hline 1183.48 & $v \mathrm{CC}-11$ & $\beta$ HCC 27 & $\beta$ HCC $34 \beta$ HCC -10 \\
\hline 1176.40 & $\beta$ HCC -11 & $\beta$ HCC 29 & $\beta$ HCC -16 \\
\hline 1144.46 & $v \mathrm{CC} 13$ & $v \mathrm{CC}-10$ & $\beta$ HCC 11 \\
\hline 1129.26 & $\beta$ CCC 12 & & \\
\hline 1120.39 & $v$ CC 15 & $\beta$ HOC -12 & \\
\hline 1108.95 & $v$ CC 21 & $v \mathrm{CC} 16$ & $\beta$ HCC 14 \\
\hline 1095.92 & $\beta$ NCC -11 & $\beta \mathrm{CCC} 16$ & $\beta$ CCC 11 \\
\hline 1071.34 & $v \mathrm{CC}-13$ & $\beta$ NCN 10 & $\beta$ CCC 11 \\
\hline 1040.96 & $\vee$ CC 18 & $\vee \mathrm{CC} 17$ & $\beta \mathrm{NCN} 14$ \\
\hline 1030.15 & $\beta \mathrm{HCC}-12$ & $\beta$ HCC 15 & $\beta$ CCC $-22 \beta$ CCN 20 \\
\hline 1017.03 & $\tau$ HCCC 62 & $\tau \mathrm{CCCC}-11$ & $\gamma$ BrCCC 12 \\
\hline 986.67 & $\tau$ HCCC -26 & $\tau$ HCCC 35 & $\tau$ HCCC -25 \\
\hline 977.49 & $\tau \mathrm{HCCC} 17$ & $\tau \mathrm{HCCC}-41$ & $\tau$ HCCC $22 \tau$ CCCC -12 \\
\hline 959.75 & $\tau$ HCCC -34 & $\tau$ HCCC 32 & $\tau \mathrm{HCCN}-20$ \\
\hline 949.14 & $\tau$ HCCC 35 & & \\
\hline 937.75 & $\tau \mathrm{HCCN} 19$ & $\tau$ HCCC 25 & $\tau$ HCCC -18 \\
\hline 934.44 & $\tau$ HCCC -26 & & \\
\hline 909.04 & $v$ NC 15 & $\beta \mathrm{CCC}-12$ & $\beta$ CCC 11 \\
\hline 892.21 & $v \mathrm{CC} \quad 17$ & & \\
\hline 867.10 & $\tau$ HCCC -15 & $\tau$ HCCN 38 & \\
\hline 863.41 & $\tau \mathrm{HCCN}-14$ & $\tau$ HCCC 15 & \\
\hline 855.9 & $\tau \mathrm{HCCN}-25$ & $\tau \mathrm{HCCC}-12$ & $\tau$ HCCC $-11 \tau$ HCCC -12 \\
\hline 854.95 & $\tau \mathrm{HCCN}-14$ & $\tau$ HCCC 23 & \\
\hline 822.22 & $v$ OC 14 & $\beta$ CCC 21 & \\
\hline 795.68 & $\beta$ CCC 16 & & \\
\hline 774.51 & $\tau \mathrm{HCCN}-10$ & $\tau \mathrm{CNCN}-28$ & \\
\hline 767.01 & $\tau$ CCCC -19 & $\gamma \mathrm{CCNC} 14$ & \\
\hline 762.57 & $\tau$ HCCC 14 & $\tau$ HCCC 15 & $\tau$ HCCC $13 \gamma$ NCCC -22 \\
\hline 756.04 & $\tau \mathrm{CCCC} 16$ & $\gamma$ OCCC -11 & \\
\hline 749.83 & $\tau \mathrm{HCCN}-17$ & $\tau$ HCCC 27 & $\tau$ HCCC $24 \tau$ HCCC 15 \\
\hline 718.20 & $\beta$ CCC 11 & & \\
\hline 702.94 & $\tau \mathrm{CCCC}-10$ & $\tau \mathrm{CCCC}-10$ & $\gamma \mathrm{CNNC}-13$ \\
\hline 690.14 & $\beta \mathrm{CCC}-11$ & $\tau \mathrm{HCCC}-12$ & $\gamma \mathrm{BrCCC} 10$ \\
\hline 670.95 & $\beta \mathrm{CCC}-10$ & $\tau \mathrm{HNCC}-13$ & \\
\hline 643.84 & $v \mathrm{BrC}-10$ & $\beta$ CCC 12 & $\beta \mathrm{CCC}-10$ \\
\hline 621.08 & $\tau$ HNCC 17 & & \\
\hline 616.99 & $\beta \mathrm{CNC}-10$ & & \\
\hline 601.51 & $\tau \mathrm{HNCC}-11$ & & \\
\hline 585.56 & $\tau \mathrm{CCCN} 25$ & $\gamma \mathrm{CCNC} 14$ & \\
\hline 579.29 & $\beta$ CCC 16 & $\beta \mathrm{CCN} 14$ & \\
\hline 556.20 & $\tau \mathrm{CCCC} 10$ & $\tau \mathrm{CCCC}-10$ & $\gamma$ NCCC -21 \\
\hline 538.08 & $\vee \mathrm{NC} 10$ & $\beta$ CCC 16 & $\tau$ HNCC -14 \\
\hline 524.48 & $\beta$ NCC 16 & $\tau$ HNCC 13 & $\tau \mathrm{CCCC} 10$ \\
\hline 493.21 & $\beta$ OCC 36 & & \\
\hline 472.30 & $\beta$ OCC 15 & $\gamma$ CNCC -10 & \\
\hline 460.38 & $\tau$ CCCC -18 & $\gamma$ OCCC -11 & \\
\hline 440.27 & $\tau$ HCCC 10 & $\tau$ CCCC 19 & $\gamma$ CNCC -40 \\
\hline 401.53 & $\beta$ CCC 22 & & \\
\hline $\begin{array}{l}387.67 \\
364.70\end{array}$ & $\tau \mathrm{CCCC}-37$ & $\gamma \mathrm{BrCCC} 13$ & $\gamma$ OCCC -20 \\
\hline 343.20 & $\tau$ HOCC 96 & & \\
\hline 338.94 & $\tau$ CCCC 11 & $\tau$ CCCC -10 & \\
\hline 316.34 & $\tau \mathrm{CCCN}-13$ & $\tau \mathrm{CNCN}-15$ & \\
\hline 296.46 & v CC 18 & $v \mathrm{BrC} 13$ & \\
\hline 289.47 & $v$ BrC 35 & & \\
\hline 249.93 & $\beta$ OCC -13 & $\beta$ CCC -12 & $\beta$ BrCC 30 \\
\hline 224.06 & $\beta$ BrCC 12 & & \\
\hline
\end{tabular}




$\begin{array}{ccc}212.31 & \gamma \text { CCCN }-11 & \\ 168.25 & \tau \text { CCCC } 13 & \gamma \text { CCCC } 18 \\ 148.35 & \beta \text { CCC } 13 & \beta \text { CCN } 18 \\ 129.54 & \tau \text { CCCC } 25 & \tau \text { CCCC }-52 \\ 116.68 & \beta \text { CCC } 19 & \beta \text { BCC } 16 \\ 108.61 & \tau \text { CCCN } 26 & \gamma \text { CCCN }-11 \\ 64.06 & \tau \text { NCNC }-15 & \tau \text { CCCC }-26 \\ 38.09 & \beta \text { CNC } 11 & \tau \text { CNCC }-12 \\ 34.71 & \beta \text { NCC }-14 & \beta \text { CCC }-11 \\ 20.48 & \tau \text { NCCC } 41 & \gamma \text { CCCC } 32\end{array}$

terms of the distribution of the highest occupied molecular orbital (HOMO) and the lowest unoccupied molecular orbital (LUMO). TD-DFT at the B3LYP/6-31++G(d,p) level of theory was used to investigate the electronic spectra and to optimize the excited state. The ionization potential and electron affinity (adiabatic and vertical) were calculated to gain insights into the hole/electron transport. The influence of electric field and its direction on the spatial distribution of HOMO and LUMO and dipole moment were studied. Our findings suggest that the substituted derivatives of 2-(5,6-dihydrobenzimidazo[1,2c] quinazolin-6-yl)-5-substituted phenol; L-H, L-Br and L$\mathbf{O C H}_{3}$ can be used as promising electron transport materials for organic light emitting diodes (OLED).

\section{ACKNOWLEDGEMENTS}

This work was supported by the Deanship of Scientific Research (DSR), King Abdulaziz University, Jeddah, under grant No. (662-852-D1435). The authors, therefore, acknowledge with thanks DSR technical and financial support.

\section{REFERENCES}

1. F.-I. Wu, C.-F. Shu, C.-H. Chien and Y.-T. Tao, Synth. Met., 148, 133 (2005);

https://doi.org/10.1016/j.synthmet.2004.09.029.

2. 2 W.-Y. Hung, L.-C. Chi, W.-J. Chen, Y.-M. Chen, S.-H. Chou and K.T. Wong, J. Mater. Chem., 20, 10113 (2010); https://doi.org/10.1039/c0jm02143a.

3. M. Nomuraa, Y. Shibasakia, M. Ueda, K. Tugitab, M. Ichikawab and Y. Taniguchib, Synth. Met., 148, 155 (2005); https://doi.org/10.1016/j.synthmet.2004.09.030.

4. M. Nomura, Y. Shibasaki, M. Ueda, K. Tugita, M. Ichikawa and Y. Taniguchi, Synth. Met., 151, 261 (2005); https://doi.org/10.1016/j.synthmet.2005.05.010.

5. J.J. Huang, M.K. Leung, T.-L. Chiu, Y.-T. Chuang, P.-T. Chou and Y.H. Hung, Org. Lett., 16, 5398 (2014); https://doi.org/10.1021/ol502602t.

6. M. Malathi, P.S. Mohan, R.J. Butcher and C.K. Venil, Can. J. Chem., 87, 1692 (2009); https://doi.org/10.1139/V09-139.

7. Y. Zhao, C. Wu, P. Qiu, X. Li, Q. Wang, J. Chen and D. Ma, Appl. Mater. Interfaces, 8, 2635 (2016); https://doi.org/10.1021/acsami.5b10464.

8. Gaussian 09, Revision A.02, M.J. Frisch, G.W. Trucks, H.B. Schlegel, G.E. Scuseria, M.A. Robb, J.R. Cheeseman, G. Scalmani, V. Barone, B. Mennucci, G.A. Petersson, H. Nakatsuji, M. Caricato, X. Li, H.P. Hratchian, A.F. Izmaylov, J. Bloino, G. Zheng, J.L. Sonnenberg, M. Hada, M. Ehara, K. Toyota, R. Fukuda, J. Hasegawa, M. Ishida, T. Nakajima, Y. Honda, O. Kitao, H. Nakai, T. Vreven, J.A. Montgomery, Jr., J.E. Peralta, F. Ogliaro, M. Bearpark, J.J. Heyd, E. Brothers, K.N.
Kudin, V.N. Staroverov, R. Kobayashi, J. Normand, K. Raghavachari, A. Rendell, J.C. Burant, S.S. Iyengar, J. Tomasi, M. Cossi, N. Rega, J.M. Millam, M. Klene, J.E. Knox, J.B. Cross, V. Bakken, C. Adamo, J. Jaramillo, R. Gomperts, R.E. Stratmann, O. Yazyev, A.J. Austin, R. Cammi, C. Pomelli, J.W. Ochterski, R.L. Martin, K. Morokuma, V.G. Zakrzewski, G.A. Voth, P. Salvador, J.J. Dannenberg, S. Dapprich, A.D. Daniels, O. Farkas, J.B. Foresman, J.V. Ortiz, J. Cioslowski, D.J. Fox, Gaussian, Inc., Wallingford CT, 2009.

9. Chemcraft software, http://www.chemcraftprog.com.

10. N.M. O'Boyle, A.L. Tenderholt and K.M. Langner, J. Comput. Chem., 29, 839 (2008); https://doi.org/10.1002/jcc.20823.

11. M.E. Köse, W.J. Mitchell, N. Kopidakis, C.H. Chang, S.E. Shaheen, K. Kim and G. Rumbles, J. Am. Chem. Soc., 129, 14257 (2007); https://doi.org/10.1021/ja073455y.

12. S.R.J. Fuyu, Arab. J. Chem.; 10.1016/j.arabjc.2013.11.037.

13. S.A. Siddiqui, A. Al-Hajry and M.S. Al-Assiri, Int. J. Quantum Chem., 116, 339 (2016); https://doi.org/10.1002/qua.25034.

14. NaserEltaherEltayeb, Siang Guan Teoh, Ching KhengQuah and HoongKun Fun, Acta Cryst., E67, o2243 (2011).

15. D. Thirion, M. Romain, J. Rault-Berthelot and C. Poriel, J. Mater. Chem., 22, 7149 (2012); https://doi.org/10.1039/c2jm16774c.

16. R.M. Silverstein, G.C. Bassler and T.C. Morrill, Spectrometric Identification of Organic Compounds. $5^{\text {th }}$ edition. New York: Wiley; (1981).

17. M.D. Halls and H.B. Schlegel, Chem. Mater, 13, 2632 (2001); https://doi.org/10.1021/cm010121d.

18. P. Srinivasan and A.D. Stephen, J. Theor. Comput. Chem., 14, 1550038 (2015); https://doi.org/10.1142/S0219633615500388.

19. A.T. Nska, K. Lewandowska, A. JeliNska, P. Garbacki, A. Podborska, P. Zalewski, I. Oszczapowicz, A. Sikora, M. Kozak and J.C.-Piontek, Scientific World J., 921049 (2015).

20. K.-H. Kim, S. Lee, C.-K. Moon, S.-Y. Kim, Y.-S. Park, J.-H. Lee, J. Woo Lee, J. Huh, Y. You and J.-J. Kim, Nat. Commun., 5, 4769 (2014); https://doi.org/10.1038/ncomms5769.

21. X.Q. Ran, J.K. Feng, A.M. Ren, W.C. Li, L.Y. Zou and C.C. Sun, J. Phys. Chem. A, 113, 7933 (2009); https://doi.org/10.1021/jp903511r.

22. L.Y. Zou, A.M. Ren, J.K. Feng, Y.L. Liu, X.Q. Ran and C.C. Sun, J. Phys. Chem. A, 112, 12172 (2008); https://doi.org/10.1021/ip8032462.

23. N.E. Gruhn, D.A. da Silva Filho, T.G. Bill, M. Malagoli, V. Coropceanu, A. Kahn and J.L. Bredas, J. Am. Chem. Soc., 124, 7918 (2002); https://doi.org/10.1021/ja0175892.

24. R.A. Marcus, Аnпu. Rev. Phys. Chem., 15, 155 (1964); https://doi.org/10.1146/annurev.pc.15.100164.001103.

25. M. Bourass, A. Touimi Benjelloun, M. Benzakour, M. Mcharfi, M. Hamidi, S.M. Bouzzine, F. Serein-Spirau, T. Jarrosson, J.P. Lère-Porte, J.M. Sotiropoulos and M. Bouachrine, J. Mater. Environ. Sci., 6, 1542 (2015).

26. D. Yokoyama, J. Mater. Chem., 21, 19187 (2011); https://doi.org/10.1039/c1jm13417e. 